\title{
Carbon Emission Performance and Regime Type - The Role of Inequality
}

Zorzeta Bakaki, Tobias Böhmelt, and Hugh Ward

University of Essex

\begin{abstract}
Existing results about the impact of regime type on states' environmental performance are inconclusive. We argue that this can stem from failure to allow for a factor that, thus far, has been largely overlooked - economic inequality. More equal democratic societies, we contend, are likely to make greater progress in dealing with environmental problems. However, inequality undermines those processes and characteristics of democratic polities that are supposed to further environmental protection. In contrast, inequality is unlikely to be of much importance in authoritarian states. We examine this argument using data on carbon emission performance for the post-1970 period. Our results provide strong and robust evidence that inequality moderates the influence of democracy on this aspect of environmental outcomes. Our research adds to the debate about regime type and environmental politics, addressing a major gap in the literature.
\end{abstract}

Keywords: Democracy, Inequality, Environmental Performance, Quantitative Analysis 


\section{Introduction}

It is often argued that democracies' domestic and international environmental policy outputs are greater than that of autocracies, and that they also perform better in terms of environmental outcomes (e.g., Congleton 1992; Payne 1995; Li and Reuveny 2006; Bernauer et al. 2013; Bättig and Bernauer 2009; Cao and Ward 2015; Böhmelt et al. 2016, 2018; Schaffer and Bernauer 2014). Yet, anecdotal evidence suggests that democracies are not necessarily better at making progress in relation to climate change. For example, Germany and the United Kingdom, wellestablished democracies and front runners in fighting climate change, lend some support to a link between democratic polities and carbon emission progress. However, the United States, Canada, and Australia lag behind - even behind some autocracies - in dealing with this issue. ${ }^{1}$ Whether democracies are "greener" than authoritarian regimes may be conditional on a number of factors such the type of pollution and whether it is of immediate concern to citizens (Bernauer and Koubi 2009; Ward 2008), the length of time a society has been a stable democracy (Fredriksson and Neumayer 2013), corruption (Povitkina 2018), or whether we consider variation in democracy between different states or democratization within a particular state (Clulow 2019).

We argue that economic inequality is another factor conditioning countries' - and especially democracies' - progress in relation to climate change. By examining this, we address a core aspect of future research discussed in Bel and Teixidó (2020: 11), namely "a promising avenue for future research is to analyze to what extent the quality of democracy might be influencing the

\footnotetext{
${ }^{1}$ For instance, see the latest (2020) ranking of the Climate Change Performance Index: the US $\left(61^{\mathrm{st}}\right)$, Canada $\left(58^{\mathrm{th}}\right)$, and Australia $\left(54^{\text {th }}\right)$ are all rated "very low" in terms of their efforts to fight climate change. In addition, none of them are on path compatible with the Paris Agreement goals. Available online at: https://germanwatch.org/en/19686.
} 
relationship between inequality and climate policy ambition." Although Kashwan (2017) shows that inequality can interact with democracy in relation to protected land areas, the way that inequality undercuts democracy in relation to other aspects of environmental performance has been largely overlooked.

Income inequality has grown in almost all countries since the 1980s, albeit at different rates and for different reasons (Alvaredo 2018), becoming of central concern to the $\mathrm{UN}^{2}$ and many NGOs, ${ }^{3}$ not least because climate change affects the poorest people and countries more severely (World Economic and Social Survey 2016). Moreover, some policies in relation to climate change, such as carbon taxes, would hit those on low incomes most. Thinking about who has responsibility for dealing with the current and potential injustices due to climate change and about just ways of distributing the cost burden of action has become a central focus of the environmental justice debate (Schlosberg 2013; Caney 2014).

Democracies vary greatly in their degree of economic inequality (Alvaredo 2018). Although it might be expected on theoretical grounds that further enfranchisement should lead to greater income equality because the income of the median voter falls and the preferred level of redistributive taxation of the median voter increases (Meltzer and Richard 1981), a number of other mechanisms could intervene, e.g., democratization may open up market opportunities largely benefiting the rich or the newly enfranchised middle class may redistribute to itself and not to the poor (Acemoglu et al. 2015). The voluminous empirical literature has not reached a

\footnotetext{
${ }^{2}$ See online at: https://www.un.org/en/desa/new-un-report-inequalities-cause-and-exacerbate-climate-impacts-poorand.

${ }^{3}$ See online at: https://www.greenpeace.org.uk/news/climate-change-inequality-climate-justice.
} 
consensus on whether inequality declines with democratization - and if any such relationship exists, it may well be weak and highly contingent (Acemoglu et al. 2015).

Following Boyce (1994), in an economically unequal society, the political power of rich people demanding lax environmental regulation may offset the pro-environmental interests of the rest of society (see also Boyce et al. 1999; Mikkelson et al. 2007). Islam (2015: 14f) illustrates this: "Canada, where the income of the top 10 per cent of the population is 9.4 times greater than the income of the bottom ten percent, had an annual per capita $\mathrm{CO}_{2}$ emission (during 2010-2014) of 14.1 tons, whereas Sweden, where the above income inequality ratio is 6.2 , had an annual per capita $\mathrm{CO}_{2}$ emission during the same period of 5.5 tons." Like Kashwan (2017), we extend the argument about inequality and environmental progress to cover both democracies and autocracies. We do so by integrating the argument with selectorate theory, which concerns whether it is in rulers' interests to supply public or private goods (Bueno de Mesquita et al. 2005; Cao and Ward 2015). We conclude that economic inequality will have little effect in autocracies (compare Kashwan 2017), but that it should reduce the impact of democracy on carbon emission performance.

We analyze time-series cross-section data on countries' progress in dealing with climate change since the 1970s. Our findings indicate that democracy does, indeed, improve this aspect of environmental performance in egalitarian societies, but it actually makes it worse if economic inequality is high. Also, as expected, inequality does not seem to be a significant factor in autocracies. Thus, we demonstrate that the impact of democracy on carbon emission progress hinges on the scope condition of inequality. This result adds to our understanding of the 
relationship between democracy and the environment, helping to explain some of the mixed findings produced by earlier studies (see also Kammerlander and Schulze 2021). This research highlights the need for democracies to address inequality and climate change together and adds significantly to the debate about regime type and environmental politics. We return to these issues in the conclusion.

\section{Carbon Emission Performance, Regime Type, and Inequality - Argument}

Several mechanisms potentially link inequality to environmental performance (for reviews, see, e.g., Cushing et al. 2015; Berthe and Elie 2015). However, the impact of inequality is likely to vary depending on whether the level of analysis is the individual, community, the nation, or the international system (see also, e.g., Fitzgerald et al. 2015; Islam 2015). We do not analyze the international dimension here.

In the literature on individual and household behavior, some suggest that demand for a clean environment grows with real income (Torras and Boyce 1998; Morse 2018; Arıkan and Günay 2021), or as basic needs are met and values shift (Inglehart 1995). If there is such an effect, the overall willingness to pay for environmental quality would increase with household wealth (Heerink et al. 2001; Kashwan 2017; Ravallion et al. 2000; Scruggs 1998). Having said that, the evidence for this relationship is more mixed than we may surmise ex-ante. Fairbrother (2012) reports that there is a positive relationship between income and individuals' willingness to pay for environmental cleanup, but the impact is of relatively minor importance compared to other covariates. Bakaki and Bernauer (2018: 66), moreover, cannot find conclusive results at the 
individual level and suggest instead that "there is considerable room for ambitious environmental policy even under adverse economic conditions." In general, it seems that income influences at the individual and household level matter significantly less "in lower income nations with poor environmental conditions" (Pampel, 2014: 57). Finally, actual consumption behavior paints a different picture to most attitudinal surveys. A number of studies finds that carbon footprint grows with income, though less than proportionally (Pottier 2021). The lifestyle of the rich is often particularly carbon intensive, e.g., consider the demand for international air travel (Galle and Hristos 2014). Ultimately, evidence at the individual and household-level may stress that concern about climate change increases with income, but the evidence for this is rather mixed and it seems that carbon consumption actually grows with personal wealth.

Turning to the community level, economic inequality may fuel status competition among individuals and households over goods that are not sustainably produced (Veblen 2005; Fitzgerald et al. 2015). Moreover, inequality can lower trust, cohesion, and cooperation (Baland et al. 2007), which hampers action to address environmental issues, the formulation of green demands directed at policymakers, and changes in households' behavior across communities (Pickett and Wilkinson 2010; Knight et al. 2017).

At the national level, according to Boyce (1994; see also Boyce et al. 1999; Downey 2015; Magnani et al. 2000; Moe 2005; Steinberg 2015), economic inequality may induce inequality in power, which in turn leads to inefficiently weak environmental regulation. The rich often stand to gain from blocking regulation (Grunewald et al. 2017: 250; see also Winters and Page 2009): as the consumers with the greatest purchasing power, this maximizes their surplus by keeping 
prices down; as the owners of productive assets, this maximizes their producer surplus, since they avoid regulatory costs. In an unequal society the "power-weighted social decision function" (Boyce 1994) fails to give rise to socially optimal decisions. On the other hand, the rich may have an interest in some forms of environmental regulation, such as conservation of some species. Small groups of rich people might not find it as easy to organize for collective action, though, and to get their way in a democratic but egalitarian society (Scruggs 1998; see Kashwan 2017; Mikkelson et al. 2007; Peluso 1993). Also, the effect of inequality may differ depending on whether the ownership stake of the rich is in dirty or in clean industries (McAusland 2003; Gassebner et al. 2008).

In summary, it is difficult for theorists to disentangle which mechanisms relating to inequality are at work and which might predominate (Berthe and Elie 2015), but a number of empirical studies support the idea that, overall, inequality decreases environmental performance (e.g., Torras and Boyce 1998; Boyce et al. 1999; Borghesi 2006; Mikkelson et al. 2007; Hübler 2017; Knight et al. 2017). Still, the empirical literature is less than conclusive, and recent research specifically on carbon emissions has not yielded consistent results (Jorgenson et al. 2016; see also Rojas-Vallejos and Lastuka 2020). With the exception of Kaswan (2017), the focus of these studies is on inequality and they neither control for democracy nor do they allow for the way in which it might undercut democratic processes. ${ }^{4}$ Like Kaswan (2017), we propose that democracy and inequality interact.

\footnotetext{
${ }^{4}$ Torras and Boyce (1998) include a human-rights indicator, which might be regarded as a proxy for democracy, alongside an inequality score, but they do not allow for the effect of human rights being conditional on the level of inequality.
} 
Liberal democracy has been linked to better environmental performance in a number of ways (Congleton 1992; Payne 1995; Li and Reuveny 2006; Bernauer et al. 2013; Bättig and Bernauer 2009). ${ }^{5}$ It is suggested that democratic political leaders respond to constituent demands, and that they aim to improve environmental performance if this will increase political support and their chances of staying in office (Anderson et al. 2017; see also Bernauer and Koubi 2009; Bernauer et al. 2013; Böhmelt 2021; Dasgupta and De Cian 2018). ${ }^{6}$ In democracies, civil liberties allow people to be better informed about environmental problems, to express their opinions more effectively, and to freely organize to influence government output. Domestic audiences in democracies that demand better environmental quality can impose higher audience costs on leaders as they are able to remove them from power more easily than in non-democratic systems (Stadelmann-Stefffen 2011). It is possible that small groups of wealthier people concerned about species conservation might find it easier to organize for collective action as a democratic society becomes more unequal (Scruggs 1998; see Kashwan 2017; Mikkelson et al. 2007; Peluso 1993). However, inequality may undercut the democratic mechanisms that might otherwise support environmental progress. Media coverage is an important factor in raising awareness of issues like climate change (Schmidt et al. 2013; Anderson et al. 2017; Bakaki et al. 2020). If wealthy groups opposed to change monopolize media ownership, it may be more difficult to arouse the public. ${ }^{7}$ Even supposing that citizens want change and press for environmental progress, if the rich are

\footnotetext{
${ }^{5}$ Political theorists (e.g., Baber and Bartlett 2005; Dryzek 2010; Meadowcroft 2004; Smith 2001) forward a range of arguments about deliberative democracy. We touch on these in the conclusion.

${ }^{6}$ Although Scruggs (1998) argues that democracy leads to unstable electoral and legislative majorities that could undercut environmental performance.

${ }^{7}$ See online at: https://www.theguardian.com/media/2020/jan/14/james-murdoch-criticises-fathers-news-outlets-forclimate-crisis-denial.
} 
powerful enough and wish to protect dirty industries, they may be able to do so through lobbying, typically threatening that jobs and investment will be lost, to the detriment of incumbent politicians' electoral chances (Lindblom 1977). Downey (2015) contends that elites actively work to create undemocratic institutions and elite-controlled organizations as means to exert their power and to oppose policies aimed at improving environmental quality. They may attempt to concentrate decision-making power, shift environmental costs to those who are less affluent, and inhibit public environmental concern (see also Downey and Strife 2010).

In sum, when the rich are opposed to stronger environmental regulation, relatively egalitarian democracies should perform better than autocracies. As Kashwan (2017: 142) expects, "effective institutions in strong democracies with low levels of inequalities [...] may ensure an "optimum" provision of public goods" - thus, a country's environmental performance should improve. However, the greater the degree of economic inequality, the lower the marginal effect of democracy on environmental progress. Here, pursuing better environmental performance is likely to lead to popular resentment that translates into "electoral consequences or formidable legal challenges, which is likely to deter policymakers" (Kashwan 2017: 141).

Moving to autocracies, Alvaredo (2018) shows that they also vary considerably in their degree of economic inequality. Historically, single-party Communist states reported levels of economic inequality much lower than some Latin-American autocracies, for instance. While Kashwan (2017: 142) argues that it is difficult to predict the effect of inequality on the size of protected areas in autocracies, we argue that, in contrast to democracies, inequality is unlikely to affect environmental performance in this kind of regime. Accounts of the contrast between 
democracy and autocracy discussed above concern the "demand side" - what citizens in general demand - or what the rich want. There is also a question about the "supply side": what is it rational for rulers to provide? Bueno de Mesquita et al. (2005) argue that leaders make rational decisions about how to build a winning support coalition from among the "selectorate" of citizens who might count politically. In a democratic system, as the size of the winning coalition approaches half the selectorate (which comprises most adult citizens), it is relatively cheaper for leaders to secure support by providing public goods, which can be enjoyed by many people without necessarily losing their value to each individual. In contrast, in an autocracy where the size of the winning coalition and the selectorate are both rather small, it is rational for rulers to provide relatively large amounts of private goods to buy support. To the extent to which their grip on power is secure, authoritarian rulers also tend to find it rational to provide infrastructural public goods to develop the economy, rather than environmental public goods (Ward, Cao, and Mukherjee 2014). For instance, in communist autocracies environmental concerns often conflict with state-led economic development priorities based on large-scale industry and military production, as in the case of the Soviet Union (Peterson 2019). Autocracies tend to be more unstable than democracies; and semi-democracies tend to be more unstable than either of these types (Knutsen and Nygård 2015). Cao and Ward (2015) argue that, even when the selectorate is sufficiently large, state capacity and regime stability have to be high enough for it to be rational for rulers to provide environmental public goods. In summary, the power of the rich will not matter as much as in a democracy to environmental performance, for it is less likely that rulers will propose environmental policies that the rich might object to. 
The composition of the selectorate in autocracies differs depending on the nature of the autocratic regime. For example, in military juntas, it might include officers leading key regiments, while the armed forces do not count as much in single-party communist regimes. However, in many authoritarian regimes, the selectorate includes the richest and most economically powerful people e.g., the members of the extended royal household in monarchical regimes (see also Geddes et al. 2014). Of course, green movements can develop under authoritarian regimes; and such regimes often develop environmental policies that may well be quite distinctive from, and sometimes more successful than, those developed in liberal democracies (Brain and Pál 2018). However, the rich are often able to get direct access to authoritarian rulers, which can prevent progress on environmental issues when it is against their interests. For example, despite some backing by politicians at provincial level, a major project under the UN's Reducing Emissions from Deforestation and Forest Degradation in Aceh province in Indonesia was blocked by corrupt links between forestry officials and powerful economic interests wishing to expand palm oil production and agriculture (Swainson and Mahanty 2018). If it is largely the very rich and powerful that count in autocracies, the degree of equality across the rest of society is not particularly politically relevant in an autocracy. As a result, we do not expect economic inequality to be significantly related to environmental progress in autocracies. 


\section{Research Design}

Our empirical analysis is based on a country-year (monadic) time-series cross-section data set comprising the relevant variables since 1970. This temporal focus is driven by the fact that the issue of climate change was publicly and widely raised for the first time in the 1970s specifically, at the 1972 Earth Summit in Stockholm. In the following, we describe the variables employed in the analysis, their operationalization and data sources; and we outline the methodology used.

A large number of the empirical studies discussed above use the level of per-capita emissions of greenhouse gases as their dependent variable. It seems to us, however, that a more appropriate variable is necessary to capture environmental performance when it comes to $\mathrm{CO}_{2}$ emissions. Specifically, our theory concerns how much effort is being put into bringing about change. Considerable effort may be applied, yet, for historical reasons, emissions may still be high in a given year. Even with the best intentions, it can take a significant amount of time to develop and implement policies, as well as to make relevant changes in social practices. Data on emissions and their levels cannot fully capture this, and it is particularly challenging to test a theory concerning the impact of regime type using such un-transformed data because democracy correlates with the level of income and, thus, with the level of emissions (Treisman 2020). For these reasons, we employ a modified progress measure based on carbon dioxide emissions (in metric tons per capita) from the World Bank Development Indicators. Carbon dioxide emissions stem from the burning of fossil fuels and the manufacture of cement. They also include carbon dioxide produced during the consumption of solid, liquid, and gas fuels and flaring. $\mathrm{CO}_{2}$ 
emissions are a major source of human-induced climate change (Solomon et al. 2009). We transform this variable into our outcome item Carbon Emission Progress.

To measure progress, we could calculate the inverse of the difference between per-capita carbon emissions in the current year and the year before. This would produce positive values if emissions were reduced and negative values if they had increased. However, we modify this to acknowledge non-linearities in the costs of reducing emissions and in damage done when emissions rise. Initially, consider increasing emissions, i.e., regress. There are tipping points in natural systems such that pushing global average temperature increase beyond them will lead to large and potentially irreversible changes in natural systems. It is now widely accepted that these can occur at increases of some $1.5^{\circ} \mathrm{C}-2^{\circ} \mathrm{C}$ above pre-industrial levels (Lenton et al. 2019). With global mixing of greenhouse-gas emissions, it is unlikely that any single country's yearly rise in emissions would push things beyond a threshold; but with low probability, there could be a massive non-linear impact. Regress may be the result of cyclical variation in economic activity, but it can also be associated with investment in relatively carbon-intensive technologies such as coal-fired electricity generation or buildings with poor insulation standards. Such investment can lead to carbon lock-in: technological lock-in whereby the long life-spans of the investment and low operating costs lead to deferring investment in more sustainable systems with higher upfront costs; behavioral lock-in, whereby patterns of consumption around the locked-in technology become habitual; and political lock-in, whereby economic interests around the unsustainable technology acquire undue influence within organizations and within government (Seto et al. 2016). Carbon lock-in commits a state to a path along which summed emissions over 
time and eventual costs of transition to sustainable technologies are higher than they might have been (Erickson et al. 2015). If this is the case, measuring regress just by the annual increase in emissions does not capture the total impact of what has happened that year.

\section{FIGURE 1}

CARBON EMISSION PROGRESS, 1970-2016

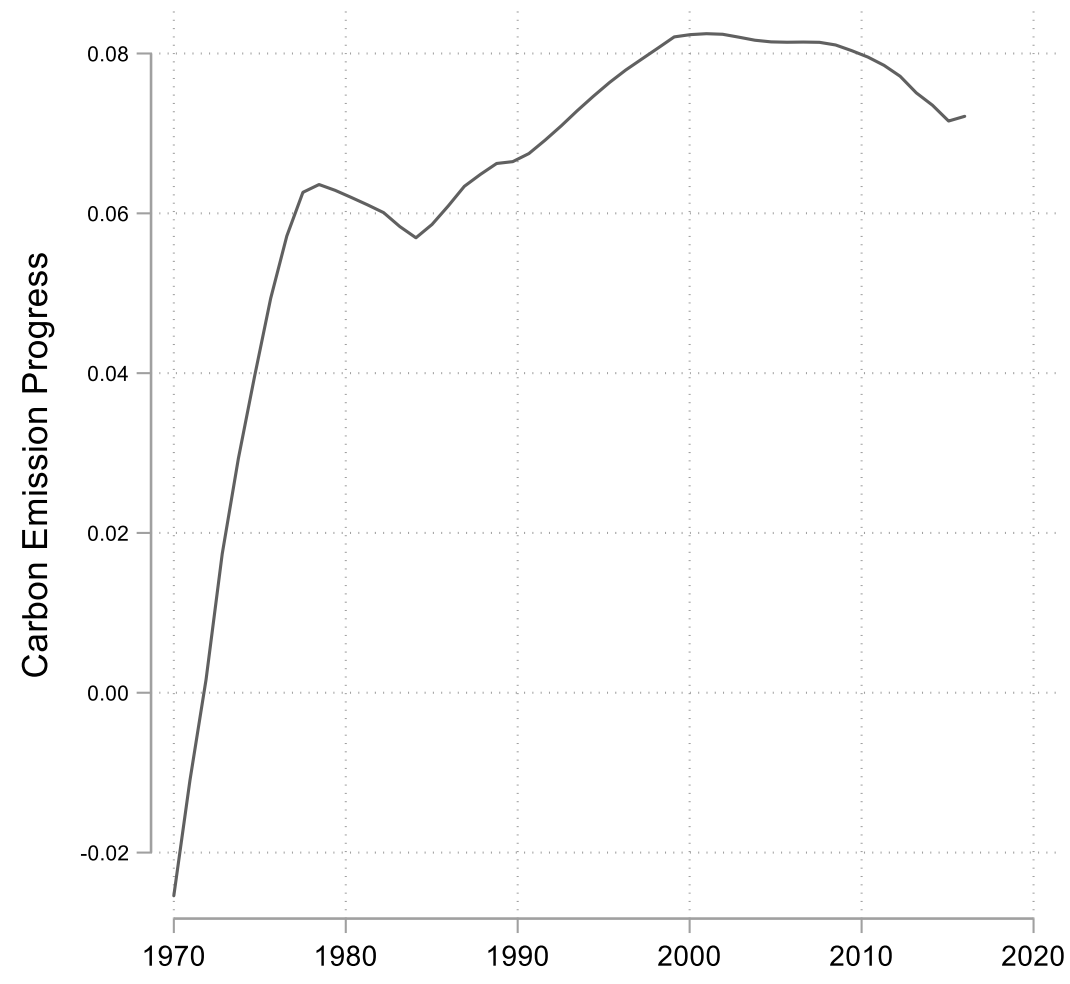

Notes. Graph displays kernel-weighted local polynomial regression of Carbon Emission Progress on time; solid line stands for smoothed values.

In relation to progress, the inverse of the above arguments holds: progress takes the global pattern further away from tipping points beyond which non-linear environmental effects occur. 
And progress brought about by investing in more sustainable technologies avoids lock-in to higher future emissions and higher transition costs. In addition, the marginal costs of emission reduction increase with the level of reduction. Informally, once the "low-hanging fruits" in terms of reductions have been picked, it becomes more difficult to make further reductions. In the light of these arguments, our measure of progress is operationalized as follows. If emissions in the current year are less than the year before, we employ $\left(\mathrm{CO}_{2}(t)-\mathrm{CO}_{2}(t-1)\right)^{2}$. If emissions in the current year are greater than or equal to the year before, our measure is $-\left(\mathrm{CO}_{2}(t)-\mathrm{CO}_{2}(t-1)\right)^{2}$.

FIGURE 2

CARBON EMISSION PROGRESS AS A FUNCTION OF EMISSION CHANGES

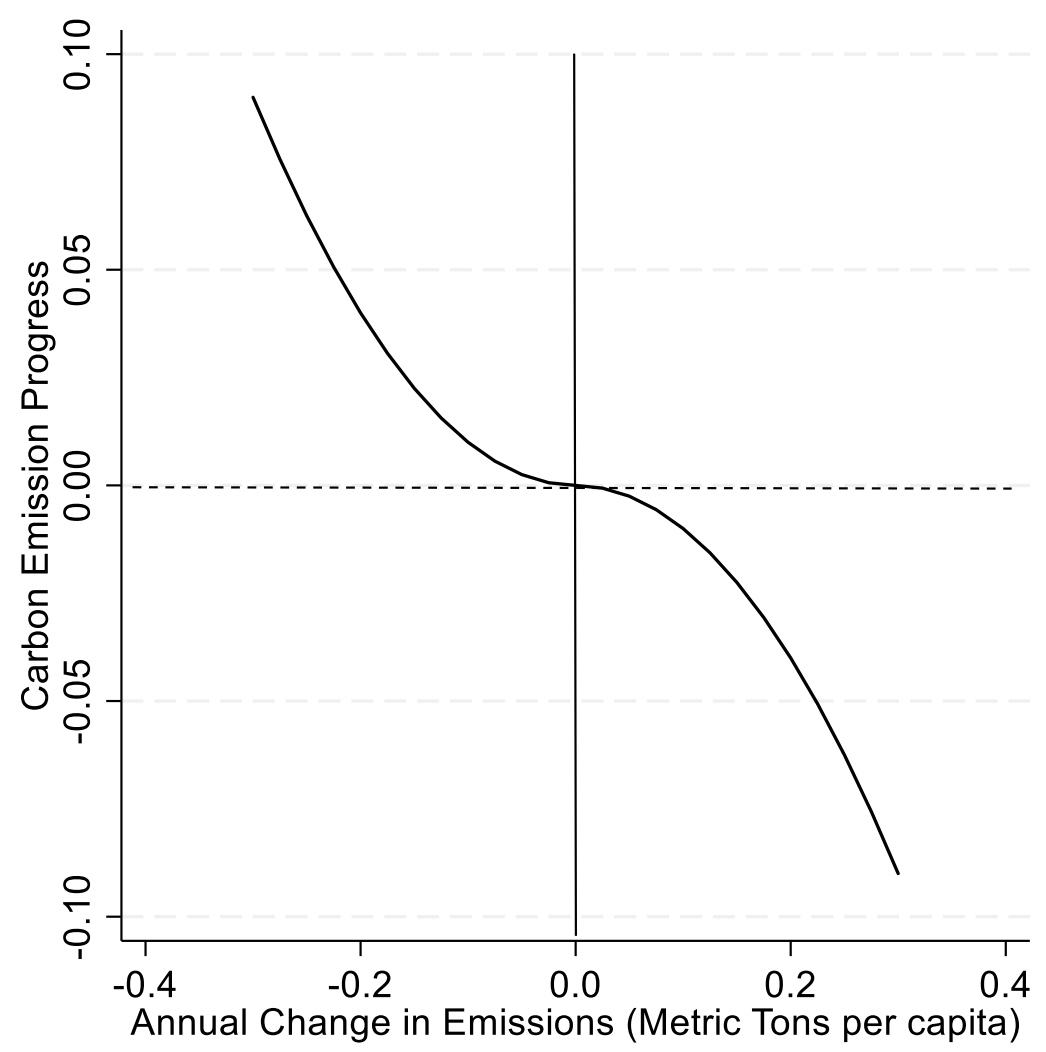


Figure 1 illustrates this variable's distribution in the period 1970-2016, while Figure 2 shows the relationship between changes in emissions and our measure of progress. OLS regression with fixed effects for years and countries is a suitable estimator given the variable of interest. The year fixed effects control for system-wide shocks affecting all countries in a similar way. The country fixed effects eliminate all between-unit variation and capture unobserved, unit-specific characteristics that are time-invariant. We explore several alternatives to this approach in the appendix.

Our core explanatory variables pertain to inequality, democracy, and a multiplicative interaction of these two items (see also Hainmueller et al. 2019). Cross-nationally comparable data on inequality is hard to obtain because of the diverse measures and methodologies used by different agencies and due to measurement error. However, the Standardized World Income Inequality Database (SWIID) overcomes some issues in this context, making data available for many countries and years, while acknowledging differences in the quality of point estimates (Solt 2020). The SWIID reports several measures, from which we use the Gini coefficient for disposable (i.e., post-tax, post-transfer) income. Because we are interested in the use of resources actually available to societal actors to undercut state action, this variable is more suitable than an inequality measure for market (pre-tax and pre-transfer) income. Standard errors are also reported for this item, reflecting the uncertainties in the data. In our case, the standard error is at 
around 0.09 and, as a result, we use this variable in standard regression techniques for the main analysis. $^{8}$

To capture regime type or states' democracy scores, we employ the Polity V data from the Center for Systemic Peace (Marshall et al. 2002). ${ }^{9}$ This variable ranges between -10 and 10 , with higher values standing for more democratic polities. In the appendix, we consider alternative data and specifications for the regime-type variable. Initially, we introduce Inequality and Democracy separately. However, as in Kashwan (2017), our full model includes the multiplicative interaction between these two variables, Inequality * Democracy, to test whether the impact of democracy is conditioned by the level of inequality (see also Hainmueller et al. 2019). Given the difficulty of interpreting an interaction term derived from two non-binary variables (Brambor et al. 2006), we calculate and present substantive quantities of interest to facilitate interpretation.

We also consider four variables that control for alternative mechanisms shaping countries' carbon performance at the outcome level (e.g., Li and Reuveny 2006; Ward 2008; Bernauer and Koubi 2009; Spilker 2012; Bernauer and Böhmelt 2013; Böhmelt et al. 2018). First, we control for the level of $\mathrm{CO}_{2}$ emissions in a given year. The higher the level of carbon emissions, the less likely it could be that progress is made to begin with. Conversely, a lower level of emissions in a given year may allow for more potential progress. Second, population and income are frequently

\footnotetext{
${ }^{8}$ The SWIID also allows estimation using multiple imputation. For each country-year, 100 values are reported with the standard deviation increasing as the quality of the data is judged to be lower. Estimation proceeds in the usual manner for multiple imputation by repeatedly drawing samples and pooling the coefficient estimates. The appendix discusses a robustness check using imputation.

${ }^{9}$ Available online at: https://www.systemicpeace.org/inscrdata.html.
} 
seen as robust predictors of environmental quality and carbon emission performance. The larger the population, the lower a state's environmental performance is likely to be. More populous countries have higher energy needs and burning fossil fuels is necessary for meeting all citizens' demands. States' usually tend to "become rich first" and clean up later (Spilker 2013) i.e., economic wealth is generally more important than environmental performance. The literature associates income with environmental quality via the Environmental Kuznets Curve (e.g., Grossman and Krueger 1991; Dasgupta et al. 2002; Savona and Ciarli 2019), i.e., depending on sample countries, years, and environmental-quality indicator considered, there may be a nonlinear relationship between the two. We are not interested in thoroughly modeling this, but merely control for an income effect (see also Aklin 2016). Both variables are taken from the World Bank Development Indicators: population is defined as a country's midyear total population, which counts all residents regardless of legal status or citizenship (except for refugees not permanently settled); we log-transform this variable. And GDP per capita (in current thousand US Dollars) is defined as the gross domestic product (GDP) divided by midyear population. ${ }^{10}$

Finally, we include is Globalization, which captures the economic, social, and political dimensions of globalization according to Dreher (2006). This variable assigns higher values to more globalized countries in the dimensions of trade (e.g., trade in goods and services, trade regulations and agreements), finance (e.g., FDI and capital account openness), interpersonal ties, information, and culture (e.g., migration and trade in cultural goods), and politics (e.g.,

\footnotetext{
${ }^{10} \mathrm{GDP}$ is the sum of gross value added by all resident producers in the economy plus any product taxes and minus any subsidies not included in the value of the products.
} 
international organizations and treaties). This is an appropriate control as increased international embeddedness - politically and economically - is related to environmental outcome measures (see Ward 2006). Table 1 presents the descriptive statistics of the variables discussed so far.

TABLE 1

DESCRIPTIVE STATISTICS

\begin{tabular}{lccccc}
\hline Variable & Obs. & Mean & Std. Dev. & Min. & Max. \\
\hline Carbon Emission Progress & 4,343 & 0.069 & 2.937 & -75.534 & 102.668 \\
Carbon Emission Level & 4,343 & 4.522 & 5.533 & 0.021 & 67.310 \\
Inequality & 4,343 & 0.389 & 0.090 & 0.195 & 0.675 \\
Democracy & 4,343 & 4.136 & 6.374 & -10 & 10 \\
Inequality * Democracy & 4,343 & 1.447 & 2.477 & -5.354 & 5.729 \\
Population (ln) & 4,343 & 16.334 & 1.564 & 12.483 & 21.044 \\
GDP per capita & 4,343 & 12.457 & 17.322 & 0.188 & 111.968 \\
Globalization & 4,343 & 56.511 & 16.603 & 18.355 & 90.984 \\
\hline
\end{tabular}

\section{Empirical Results}

Table 2 summarizes the main results of our analysis. Models 1-3 mirror to a large degree the specifications of typical models on carbon-emission performance at the outcome level. We include the controls in all models, but vary the inclusion of the components of the interaction effect: Model 1 includes only Inequality, Model 2 includes only Democracy, while Model 3 incorporates both variables at the same time, but without the multiplicative specification. The latter is included in Model 4, which constitutes our preferred model. Focusing on the core variables of interest, the results are fairly mixed across the first three models. While Inequality and Democracy are consistently negatively signed, they do not achieve conventional levels of 
statistical significance. Thus, there is inconclusive evidence on the impact of either variable on carbon-emission performance, which mirrors the ambiguous findings in the existing literature. We now add the interaction between Inequality and Democracy in Model 4, which allows for a direct empirical test of our argument.

TABLE 2

CARBON EMISSION PROGRESS, REGIME TYPE, AND INEQUALITY

\begin{tabular}{lllll}
\hline & Model 1 & Model 2 & Model 3 & Model 4 \\
\hline Carbon Emission Level & -0.465 & -0.449 & -0.465 & -0.472 \\
& $(0.215)^{*}$ & $(0.215)^{*}$ & $(0.215)^{*}$ & $(0.214)^{*}$ \\
Inequality & -7.772 & & -7.829 & -6.231 \\
& $(4.896)$ & & $(4.868)$ & $(4.677)$ \\
Democracy & & -0.004 & -0.006 & 0.162 \\
& & $(0.011)$ & $(0.011)$ & $(0.079)^{*}$ \\
Inequality * Democracy & & & & -0.400 \\
& & & & $(0.190)^{*}$ \\
Population (ln) & 2.686 & 2.904 & 2.717 & 2.841 \\
& $(1.320)^{*}$ & $(1.399)^{*}$ & $(1.327)^{*}$ & $(1.352)^{*}$ \\
GDP per capita & 0.039 & 0.036 & 0.038 & 0.036 \\
& $(0.028)$ & $(0.028)$ & $(0.028)$ & $(0.028)$ \\
Globalization & 0.046 & 0.042 & 0.046 & 0.041 \\
& $(0.033)$ & $(0.034)$ & $(0.033)$ & $(0.031)$ \\
\hline Observations & 4,343 & 4,343 & 4,343 & 4,343 \\
Country Fixed Effects & Yes & Yes & Yes & Yes \\
Year Fixed Effects & Yes & Yes & Yes & Yes \\
Prob $>$ F & 0.000 & 0.000 & 0.000 & 0.000 \\
\hline
\end{tabular}

Notes. Table entries are coefficients; standard errors clustered on country in parentheses; constant as well as year and country fixed effects included in all models, but omitted from presentation.

$* \mathrm{p}<0.05$ (two-tailed). 
In Model 4, Democracy now has a positive coefficient and is statistically significant at the 5 percent level. This suggests that more democratic countries are linked to more progress in fighting climate change, but only when Inequality is set to 0. However, there is no single country in our data set, which is coded as a completely equal society and, hence, a more thorough examination of the substantive effects is warranted (see also Hainmueller et al. 2019; Brambor et al. 2006). The coefficient estimate of Inequality * Democracy is negative and significant, which highlights that the positive effect of Democracy on carbon progress becomes smaller with higher values of Inequality. This mirrors our theoretical expectation. To assess the validity of this estimate, we first simulate the coefficient of Inequality * Democracy 1,000 times using the method in King et al. (2000). Figure 3 summarizes the results: the mean value of the simulated parameter is close to our estimate in Table $1(-0.400$ vs -0.417$)$. Moreover, out of these 1,000 simulations, only about 1.1 percent of cases have a coefficient estimate of greater than or equal to 0 . Hence, there is robust evidence emphasizing that the interaction between Inequality and Democracy is, in fact, negative and statistically significant. 
FIGURE 3

\section{SUBSTANTIVE QUANTITIES OF INTEREST: SIMULATED INTERACTION EFFECT}

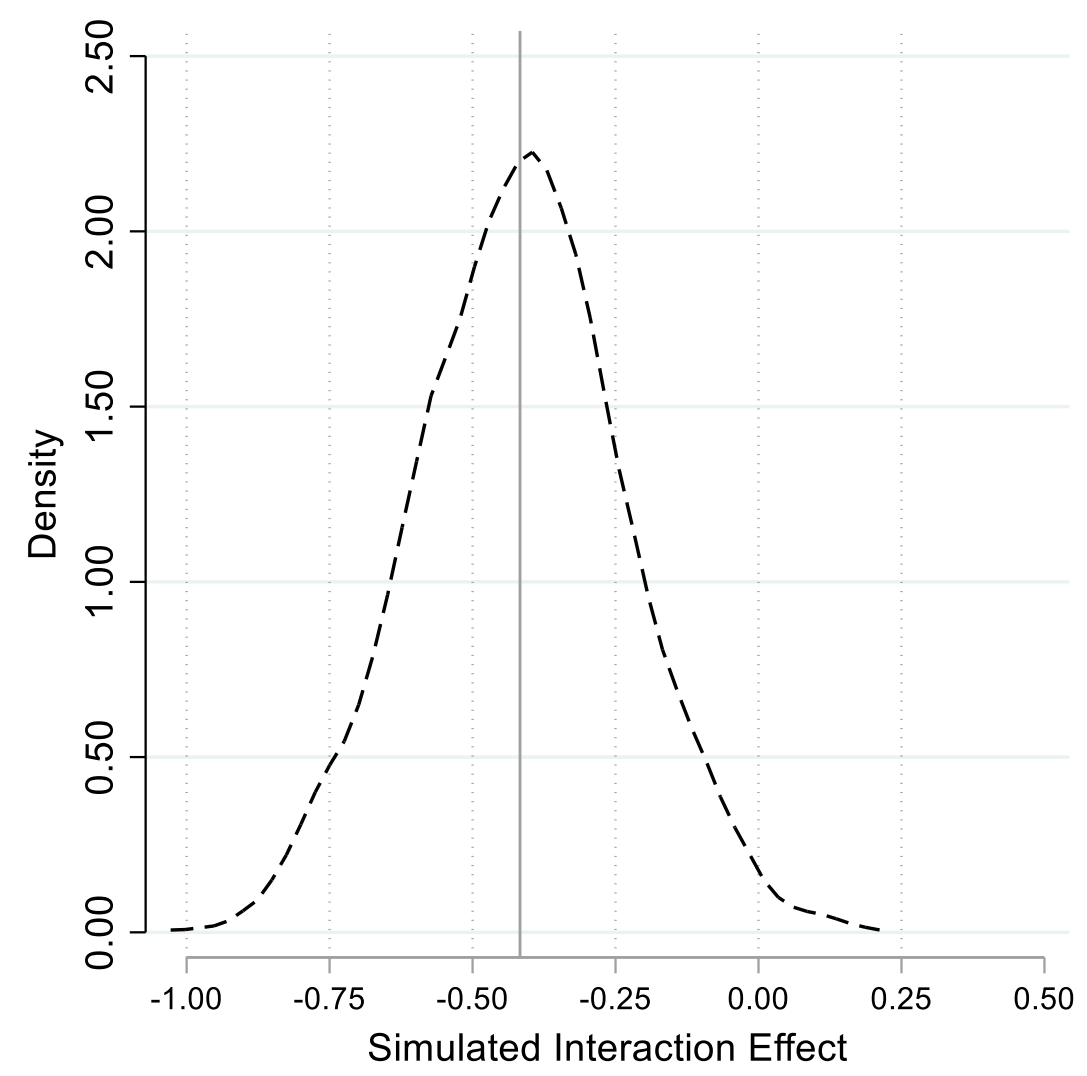

Notes. Graph displays distribution of simulated interaction effects ( $\mathrm{N}=1,000$ simulations); solid line stands for mean value of interaction effect (-0.417).

Second, we calculate marginal effects of Democracy for given values of Inequality. Figure 4 depicts the findings and sheds light on why the literature on climate change may have produced mixed effects for democratic regimes when examining the impact on environmental outcomes without the interaction with Inequality. We obtain a positive and significant marginal effect of Democracy for low levels of economic inequality. Until about a value of Inequality of about 0.35, more democratic countries are robustly linked to better environmental performance. 
However, this influence then becomes insignificant, before turning significant again but exerting a negative effect for inequality scores of about 0.45 and higher. Hence, in highly unequal societies, democratic forms of government are associated with lower environmental performance. The median value of Inequality is 0.39 , which means that about half of our sample observations are associated with lower inequality - and better environmental performance if they are also democratic. Only about 10 percent of our data set features inequality values of 0.50 or more.

Hainmueller et al. (2019) point out that multiplicative interaction models are based on two crucial requirements. On one hand, there must be a sufficient amount of "common support" to reliably compute the conditional marginal effects, i.e., cases for which the values of the moderating variable are actually observed. Second, the interactive effect is linear to the extent that, in our case, the impact of Democracy changes at a constant rate with the moderating variable of inequality. We meet the first requirement, which is demonstrated via the rug plot in Figure 4. To test for the second requirement of a linear effect, Hainmueller et al. (2019) suggest a scatterplot as a diagnostic tool for assessing whether a linear effect exists or not: that is, they recommend splitting the sample into equally sized groups based on the moderating variable, i.e., Inequality. In turn, one has to plot the outcome against the key independent variable, i.e., Democracy, while imposing a linear regression line and a Locally Weighted Scatterplot Smoothing (lowess) smoothing line. If a linear effect exists, the linear regression line should not significantly depart from the lowess line across the different groups as identified by the moderator values. We divided the sample into four equally sized groups in light of the 
distribution of Inequality. When imposing linear regression lines on the lowess lines, there are some deviations per group, but they are not statistically significantly different from each other. Still, we also examined a non-linear impact in our main model by adding a squared term of Democracy to the specification and interacting this as well with Inequality. The corresponding finding is virtually identical to what we present in Model 4.

FIGURE 4

\section{SUBSTANTIVE QUANTITIES OF INTEREST: MARGINAL EFFECTS}

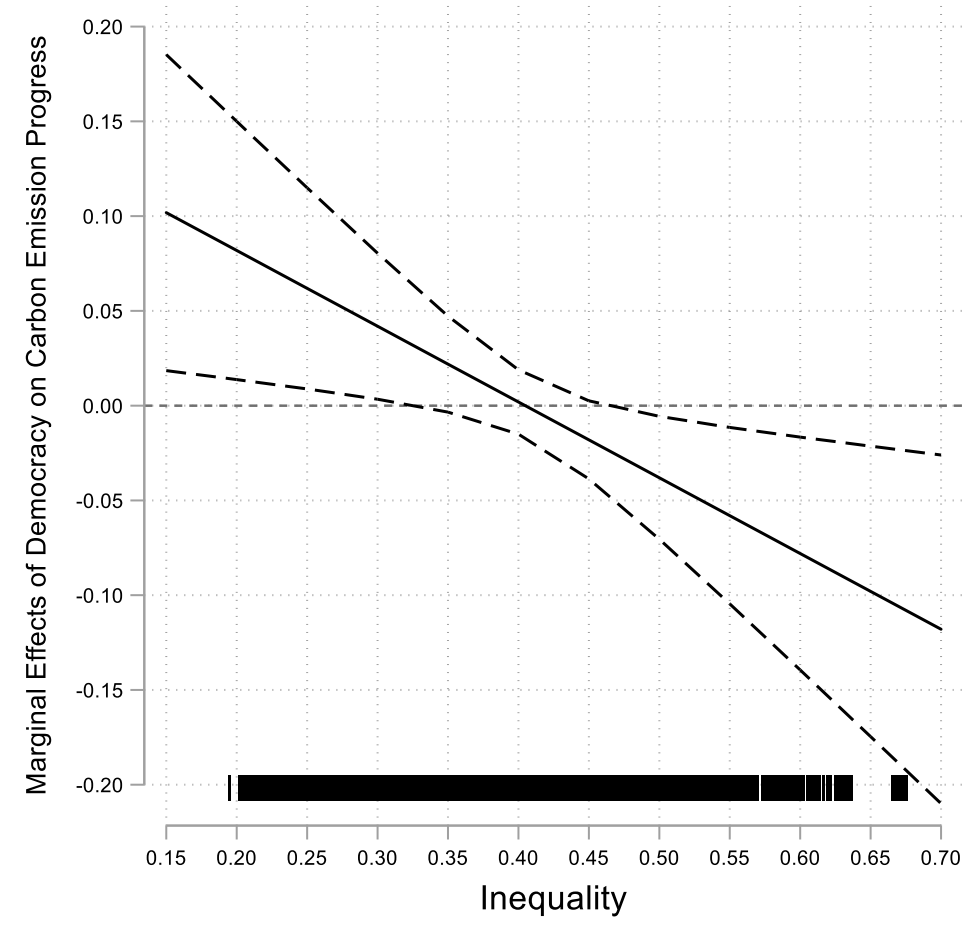

Notes. Graph displays marginal effects of Democracy for given values of Inequality; dashed lines stand for 90 percent confidence interval; rug plot at horizontal axis illustrates distribution of Inequality; horizontal dotted line marks marginal effect of 0 . 


\section{FIGURE 5}

\section{MARGINAL EFFECTS OF INEQUALITY}

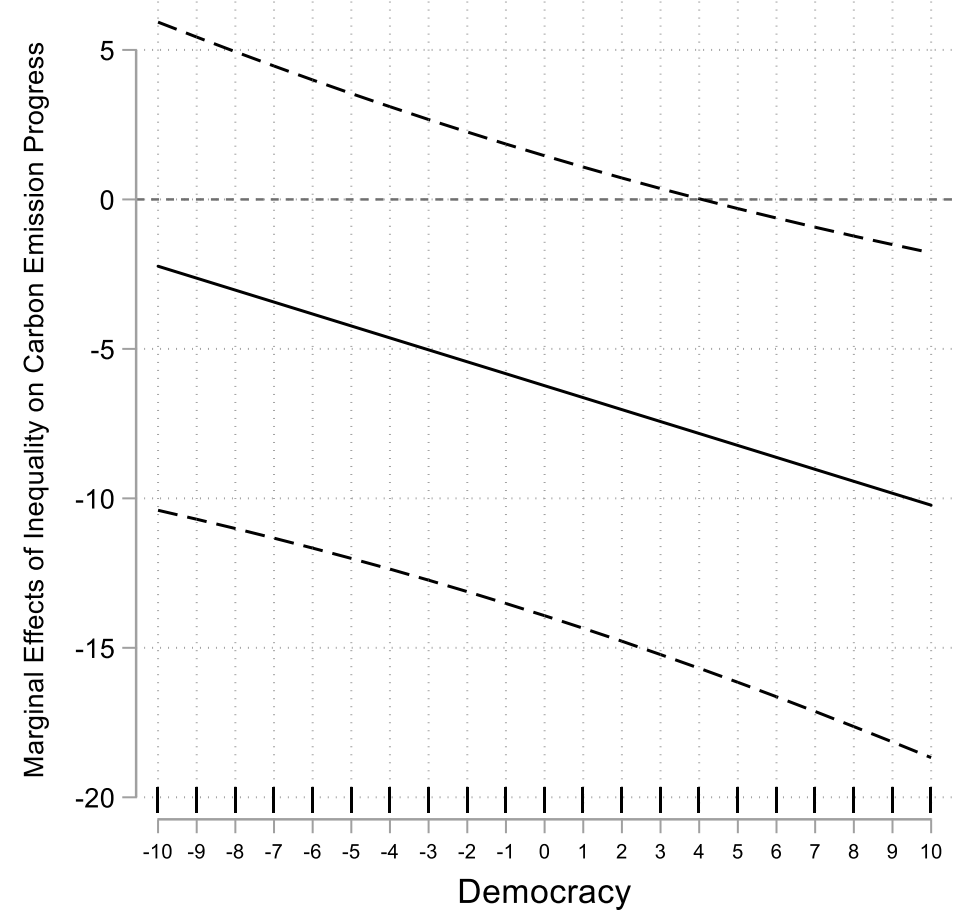

Notes. Graph displays marginal effects of Inequality for given values of Democracy; dashed lines stand for 90 percent confidence interval; rug plot at horizontal axis illustrates distribution of Democracy; horizontal dotted line marks marginal effect of 0 .

Recall that our theoretical argument also predicts that inequality should not have a significant effect in autocracies. We thus plot the marginal effects of Inequality for given values of Democracy in Figure 5, which is based on Model 4 above. The impact we estimate is indistinguishable from 0 until about a Democracy score of 5. Full democracies are commonly taken as having Polity scores of six or greater. Connecting these findings back to our theory, there is strong and robust support for a positive effect of democratic forms of government in 
relation to progress on climate change, but only in relatively egalitarian societies. In addition, inequality does not have a significant impact on this aspect of environmental performance in non-democratic regimes. In more unequal societies, conversely, the positive effect of democratic regime type disappears and, in fact, becomes negative: the mechanisms associated with democracies producing more progress appear to be offset under those circumstances and it seems that more democratic countries are actually linked to less progress on carbon emissions.

Turning to the control variables, our estimates are consistent across the models in Table 1. First, Carbon Emission Level is negatively signed and statistically significant in all our models. The higher the overall level of emissions, the more difficult it is to actually make any progress on fighting climate change. Second, the larger the population of a country, the more progress it makes on lowering carbon emissions. GDP per capita and Globalization are statistically insignificant in each model.

In the appendix, we provide a series of additional models that show for each estimation, even when varying the dependent variable or the measurement of democracy, that the negative interaction between democracy and inequality is statistically significant. The rationale behind these tests and further analyses is to assess the robustness of our main finding using different estimation procedures, variable specifications and data sources, as well as data samples. First, we examine autocorrelation and present a model with a lagged dependent variable and a PraisWinsten regression with panel-corrected standard errors. Second, we estimate models with the level of $\mathrm{CO}_{2}$ emissions as an alternative outcome variable. Third, to address concerns about endogeneity and reverse causality, we use a generalized method of moments dynamic panel 
estimator for the level of carbon emissions and our progress variable. Fourth, we explore the possibility of a curvilinear effect of population. Fifth, we employ a dichotomous specification of Democracy and consider alternative data for countries' regime type. Sixth, we use data from the V-Dem Project and control for the influence of civil society. Seventh, we explore the main effect in the pre- and post-1992 periods, and we plot the core coefficient of interest for 2-year rolling intervals. Eighth, we control for state capacity and we replaced the year fixed effects by regionyear fixed effects. We also examine the moderating influences of economic development and fossil-fuel rents, we employ multiple imputation, a different variable for globalization, and we re-estimate the core model for sub-samples of inequality. Finally, we explore the relationship between income and support for environmental policies at the individual level. The appendix also gives an overview of which countries are included in our analysis and presents a correlation matrix of the core variables.

\section{Conclusion}

There is an extensive literature on the relationship between democratic regime type and environmental output, outcomes, and especially carbon emission performance. Until now, the literature has found little conclusive evidence that democracies are indeed more environmentalfriendly and perform better than autocracies (see also Kammerlander and Schulze 2021). We seek to contribute addressing this ambiguity further by providing an analysis that focuses on the scope conditions of the environment-regime type nexus, arguing that inequality is an important

moderating factor. We argue that democracy should be linked to better carbon emission 
performance, but only when inequality is rather low. Conversely, when inequality is high and the rich oppose tighter environmental regulation, those characteristics of a democratic system that are linked to more progress in fighting carbon emissions are unlikely to be effective; indeed, we found that democracies may actually be associated with worse environmental performance under these circumstances. Our analysis of data since the 1970s supports our theory: inequality moderates the influence of democracy on carbon emission performance. While democracies have often been expected to perform better, inequality seems to be an obstacle to better environmental performance, as in the case of carbon emissions.

This finding contributes to the literature in several significant respects. First, we shed new light on the ambiguity surrounding earlier mixed results on how democracy could be linked to environmental quality. Except for Kashwan's (2017) research on protected areas, previous studies have not accounted for the moderating effect of inequality, and we show that existing mixed patterns may be explained when considering inequality as a scope condition. Second, we also add to our understanding of the determinants of environmental quality at the outcome level as well as to conceptual understanding. Particularly with regard to the latter, we have introduced carbon emission progress, a variable based on $\mathrm{CO}_{2}$ emissions that comprises countries' actual progress in their fight against global warming.

Several policy implications and avenues for future research follow from our study. Progress in relation to the environmental agenda has many dimensions beside carbon emissions, e.g., maintaining biodiversity, dealing with ground-level air pollution, and the problem of plastic waste pollution in seas. Even in relation to climate change, reducing carbon emissions is only 
one aspect of performance, e.g., measures to increase resilience and to adapt to climate change are also important. Although our theoretical argument should generally apply, it is important that further empirical studies of the way that the interaction between democracy and inequality affect performance are carried, going beyond protected areas (Kashwan 2017) and carbon emissions.

We know that democracy and inequality can cluster in space. Exploring the spatial dependencies of the moderating influence of the latter in a study of democracy and inequality may further increase our understanding of what really improves countries' environmental performance. For instance, do countries perform worse if their neighbors are inegalitarian societies that they compete with for investment and trade?

Democratic leaders who want to improve their countries' performance may have to simultaneously address inequality and environmental policy. The US is a good example of a highly unequal democratic society with a rather poor environmental outcome record in relation to climate change. In his first hundred days in office in 2021, President Bidden has prioritized both inequality and climate change. ${ }^{11}$ However, he will undoubtedly face resistance from wellfunded opponents in the coal and oil industries when attempting to get his climate policy through Congress. Can the US deal with climate change without addressing economic and political inequality first? Can it introduce effective carbon taxes and, at the same time, offset the effects on inequality and on the ability of poor citizens to meet their needs?

Finally, our work has implications for the understanding of democracy in environmental politics and the debate about "which system works best." Political theorists often claim that

\footnotetext{
${ }^{11}$ See https://www.bbc.co.uk/news/world-us-canada-56903805.
} 
liberal democracy is unlikely to be sufficient, and a different deliberative form of democracy is needed to further environmental protection (e.g., Baber and Bartlett 2005; Dryzek 2010; Meadowcroft 2004; Smith 2001; Böhmelt et al. 2016). In light of our work, inequality is likely to undercut deliberative democracy, too. In the appendix, we provide some evidence that inequality does undercut the effect of deliberative democracy, though it appears not to impact on the effect of a strong civil society. Shedding light on these causal processes is an important potential new direction for scholarship.

\section{References}

Acemoglu, Daron, Suresh Naidu, Pascual Restrepo, and James A. Robinson. "Democracy, redistribution, and inequality." In Handbook of income distribution, vol. 2, pp. 1885-1966. Elsevier, 2015.

Aklin, Michaël. 2016. Re-exploring the trade and environment nexus through the diffusion of pollution. Environmental and Resource Economics 64(4): 663-682.

Alvaredo, Facundo. 2018. The World Inequality Report. Cambridge, MA: Harvard University Press.

Anderson, Brilé, Tobias Böhmelt, and Hugh Ward. 2017. Public opinion and environmental policy output: A cross-national analysis of energy policies in Europe. Environmental Research Letters 12(11): 114011.

Arikan, Gizem, and Defne Günay. 2021. Public attitudes towards climate change: A crosscountry analysis. British Journal of Politics and International Relations 23(1): 158-174. 
Baber, Walter, and Robert Bartlett. 2005. Deliberative environmental politics. Cambridge, MA: MIT Press.

Bakaki, Zorzeta and Thomas Bernauer. 2018. Do Economic Conditions Affect Public Support for Environmental Policy? Journal of Cleaner Production 195: 66-78.

Bakaki, Zorzeta, Tobias Böhmelt, and Hugh Ward 2020. The triangular relationship between public concern for environmental issues, policy output, and media attention. Environmental Politics 29(7): 1157-1177.

Baland, Jean-Marie, Bardhan, Pranab, and Bowles, Samuel. 2007. Introduction to inequality, cooperation and environmental sustainability. In Bardhan, Pranab K., Jean-Marie Baland, and Samuel Bowles. Inequality, Cooperation, and Environmental Sustainability. Princeton, NJ: Princeton University Press.

Bättig, Michèle and Bernauer, Thomas, 2009. National institutions and global public goods: Are democracies more cooperative in climate change policy? International Organization 63(2): 281-308.

Bel, Germà, and Jordi J. Teixidó. 2020. The political economy of the Paris Agreement: Income inequality and climate policy. Journal of Cleaner Production 258(1): 121002.

Bernauer, Thomas, and Tobias Böhmelt. 2013. Are economically "kinder, gentler societies" also greener? Environmental Science \& Technology 47(21): 11993-12001.

Bernauer, Thomas, Böhmelt, Tobias, and Koubi, Vally, 2013. Is there a democracy-civil society paradox in global environmental governance? Global Environmental Politics 13(1): 88-107. 
Bernauer, Thomas, and Vally Koubi. 2009. Political determinants of environmental quality. Ecological Economics 68(5): 1355-1365.

Berthe, Alexandre, and Luc Elie. 2015. Mechanisms explaining the impact of economic inequality on environmental deterioration. Ecological Economics 116(1): 191-200.

Böhmelt, Tobias. 2021. Populism and Environmental Performance. Global Environmental Politics 21(3): 97-123.

Böhmelt, Tobias, Marit Böker, and Hugh Ward. 2016. Democratic inclusiveness, climate policy outputs, and climate policy outcomes. Democratization 23(7): 1272-1291.

Böhmelt, Tobias, Farzad Vaziri, and Hugh Ward. 2018. Does green taxation drive countries towards the carbon efficiency frontier? Journal of Public Policy 38(4): 481-509.

Boyce, James K. 1994. Inequality as a cause of environmental degradation. Ecological Economics 11(3): 169-178.

Boyce, James K., Andrew R. Klemer, Paul H. Templet, and Cleve E. Willis. 1999. Power distribution, the environment, and public health: A State-level Analysis. Ecological Economics 29(1): 127-140.

Borghesi, Simone. 2006. Income inequality and the environmental Kuznets curve. In Marcello Basili, Maurizio Franzini, and Alessandro Vercelli. Environment, inequality and collective action. London: Routledge.

Brain, Stephen, and Viktor Pál (eds.). 2018. Environmentalism under Authoritarian Regimes: Myth, Propaganda, Reality. London: Routledge. 
Brambor, Thomas, William Roberts Clark, and Matt Golder. 2006. Understanding interaction models: Improving empirical analyses. Political Analysis 14(1): 63-82.

Bueno de Mesquita, Bruce, Alastair Smith, Randolph M. Siverson, and James D. Morrow. 2005. The logic of political survival. Cambridge, MA: MIT Press.

Caney, Simon. 2014. Two kinds of climate justice: avoiding harm and sharing burdens. Journal of Political Philosophy 22(2): 125-149.

Cao, Xun, and Hugh Ward. 2015. Winning coalition size, state capacity, and time Horizons: An application of modified selectorate theory to environmental public goods provision. International Studies Quarterly 59(2): 264-279.

Clulow, Zeynep. 2019. Democracy, electoral systems, and emissions: Explaining when and why democratization promotes mitigation. Climate Policy 19(2): 244-257.

Congleton, Roger D. 1992. Political institutions and pollution control. Review of Economics and Statistics 74(3): 412-421.

Cushing, Lara, Rachel Morello-Frosch, Madeline Wander, and Manuel Pastor. 2015. The haves, the have-nots, and the health of everyone: the relationship between social inequality and environmental quality. Annual Review of Public Health 36(1): 193-209.

Dasgupta, Susmita, Benoit Laplante, Hua Wang, and David Wheeler. 2002. Confronting the environmental Kuznets Curve. Journal of Economic Perspectives 16(1): 147-168.

Downey, Liam. 2015. Inequality, democracy, and the environment. New York: New York University Press. 
Downey, Liam and Susan Strife. 2010. Inequality, democracy, and the environment. Organization \& Environment 23(2): 155-188.

Dryzek, John S. 2010. Foundations and frontiers of deliberative governance. Oxford: Oxford University Press.

Erickson, Peter, Sivan Kartha, Michael Lazarus, and Kevin Tempest. 2015. Assessing Carbon Lock-In. Environmental Research Letters 10(8): 084023.

Fairbrother, Malcolm. 2013. Rich people, poor people, and environmental concern: Evidence across nations and time. European Sociological Review 29(5): 910-922.

Fitzgerald, Jared B., Andrew K. Jorgenson, and Brett Clark. 2015. Energy consumption and working hours: a longitudinal study of developed and developing nations, 19902008. Environmental Sociology 1(3): 213-223.

Fredriksson, Per G., and Eric Neumayer. 2013. Democracy and climate change policies: Is history important? Ecological Economics 95(1): 11-19.

Gallet, Craig A., and Hristos Doucouliagos. 2014. The income elasticity of air travel: A metaanalysis. Annals of Tourism Research 49: 141-155.

Gassebner, Martin, Noel Gaston, and Michael J. Lamla. 2008. Relief for the environment? The importance of an increasingly unimportant industrial sector. Economic Inquiry 46(2): 160178.

Geddes, Barbara, Joseph Wright, and Erica Frantz. 2014. Autocratic breakdown and regime transitions: A new data set. Perspectives on Politics 12(2): 313-331. 
Grossman, Gene, and Alan Krueger. 1991. Environmental impacts of a North American Free Trade Agreement. NBER Working Papers 3914, National Bureau of Economic Research.

Grunewald, Nicole, Stephan Klasen, Inmaculada Martínez-Zarzoso, and Chris Muris. 2017. The trade-off between income inequality and carbon dioxide emissions. Ecological Economics 142(C): 249-256.

Hainmueller, Jens, Jonathan Mummolo, and Yiqing Xu. 2019. How much should we trust estimates from multiplicative interaction models? Simple tools to improve empirical practice. Political Analysis 27(2): 163-192.

Heerink, Nico, Abay Mulatu, and Erwin Bulte. 2001. Income inequality and the environment: Aggregation bias in environmental Kuznets curves. Ecological Economics 38(3): 359-367.

Hübler, Michael. 2017. The inequality-emissions nexus in the context of trade and development: a quantile regression approach. Ecological Economics 134(C): 174-185.

Islam, S. Nazrul. 2015. Inequality and environmental sustainability. UN Department of Economic and Social Affairs (DESA) Working Papers.

Inglehart, Ronald. 1995. Public support for environmental protection: Objective problems and subjective values in 43 societies. PS: Political Science \& Politics 28(1): 57-72.

Jorgenson, Andrew K., Juliet B. Schor, Kyle W. Knight, and Xiaorui Huang. 2016. Domestic inequality and carbon emissions in comparative perspective. Sociological Forum 31(S1): 770786.

Kammerlander, Andreas, and Günther G. Schulze. 2021. Political-economic correlates of environmental policy. Environmental Research Letters 16(2): 024047 
Kashwan, Prakash. 2017. Inequality, democracy, and the environment: A cross-national analysis. Ecological Economics 131(1): 139-151.

King, Gary, Michael Tomz, and Jason Wittenberg. 2000. Making the most of statistical analyses: Improving interpretation and presentation. American Journal of Political Science 44(2): 347361.

Knight, Kyle W., Juliet B. Schor, and Andrew K. Jorgenson. 2017. Wealth inequality and carbon emissions in high-income countries. Social Currents 4(5): 403-412.

Knutsen, Carl Henrik, and Håvard Mokleiv Nygård. 2015. Institutional characteristics and regime survival: Why are semi-democracies less durable than autocracies and democracies?. American Journal of Political Science 59(3): 656-670.

Lenton, Timothy M., Johan Rockström, Owen Gaffney, Stefan Rahmstorf, Katherine Richardson, Will Steffen, and Hans Joachim Schellnhuber. 2019 Climate Tipping Points - too risky to bet against. Nature 575: 592-595.

Li, Quan, and Rafael Reuveny. 2006. Democracy and environmental degradation. International Studies Quarterly 50(4): 935-956.

Lindblom, Charles E. 1977. Politics and markets: The world's political-economic systems. New York: Basic Books.

Marshall, Monty, Ted Robert Gurr, Christian Davenport, and Keith Jaggers. 2002. Polity IV, 1800-1999: Comments on Munck and Verkuilen. Comparative Political Studies 35(1): 40-45.

McAusland, Carol. 2003. Voting for pollution policy: the importance of income inequality and openness to trade. Journal of International Economics 61(2): 425-451. 
Meadowcroft, James. 2004. Deliberative Democracy. In Robert F. Durant, Daniel J. Fiorino, and Rosemary O'Leary. Environmental governance reconsidered: Challenges, choices and opportunities. Cambridge, MA: MIT Press.

Meltzer, Allan M. and Scott F. Richard. 1981. A Rational Theory of the Size of Government, Journal of Political Economy 89(3), 914-927.

Mikkelson, Gregory M., Andrew Gonzalez, and Garry D. Peterson. 2007. Economic inequality predicts biodiversity loss. PloS One 2(5): e444.

Moe, Terry M. 2005. Power and political institutions. Perspectives on Politics 3(2): 215-233.

Morse, Stephen. 2018. Relating environmental performance of nation states to income and income inequality. Sustainable Development 26(1): 99-115.

Neumayer, Eric. Sustainability and inequality in human development. 2011. UNDP-HDRO Occasional Papers 2011/4.

Pampel, Fred C. 2014. The Varied Influence of SES on Environmental Concern. Social Science Quarterly 95(1): 57-75.

Payne, Rodger A. 1995. Freedom and the environment. Journal of Democracy 6(3): 41-55.

Peluso, Nancy Lee. 1993. Coercing conservation? The politics of state resource control. Global Environmental Change 3(2): 199-217.

Peterson, Demosthenes James. 2019. Troubled lands: The legacy of Soviet environmental destruction. Routledge.

Pickett, Kate, and Richard Wilkinson. 2010. The spirit level: Why equality is better for everyone. London: Penguin. 
Pottier, Antonin. 2021. Expenditure-elasticity and income-elasticity of GHG emissions-a survey of literature on household carbon footprint. FAERE-French Association of Environmental and Resource Economists Working Papers 2021.01.

Povitkina, Marina. 2018. The limits of democracy in tackling climate change. Environmental Politics 27(3): 411-432.

Ravallion, Martin, Mark Heil, and Jyotsna Jalan. 2000. Carbon emissions and income inequality. Oxford Economic Papers 52(4): 651-669.

Rojas-Vallejos, Jorge, and Amy Lastuka. 2020. The income inequality and carbon emissions trade-off revisited. Energy Policy 139(1): 111302.

Savona, Maria, and Tommaso Ciarli. 2019. Structural changes and sustainability. A selected review of the empirical evidence. Ecological Economics 159(C): 244-260.

Schaffer, Lena and Bernauer, Thomas, 2014. Explaining government choices for promoting renewable energy. Energy Policy 68(1): 15-27.

Schlosberg, David, 2013. Theorising environmental justice: the expanding sphere of a discourse. Environmental Politics 22(1): 37-55.

Schmidt, Andreas, Ana Ivanova, and Mike S. Schäfer. 2013. Media attention for climate change around the world: A comparative analysis of newspaper coverage in 27 countries. Global Environmental Change 23(5): 1233-1248.

Scruggs, Lyle. 1998. Political and economic inequality and the environment. Ecological Economics 26(3): 259-275. 
Seto, Karen C., Steven J. Davis, Ronald B. Mitchell, Eleanor C. Stokes, Gregory Unruh, and Diana Ürge-Vorsatz. 2016. Carbon lock-in: types, causes, and policy implications. Annual Review of Environment and Resources 41(1): 425-452.

Smith, G. 2001. Taking Deliberation Seriously: Institutional Design and Green Politics. Environmental Politics 10(3): 72-93.

Solomon, Susan, Gian-Kasper Plattner, Reto Knutti, and Pierre Friedlingstein. 2009. Irreversible climate change due to carbon dioxide emissions. Proceedings of the National Academy of Sciences 106(6): 1704-1709.

Solt, Frederick. 2020. Measuring income inequality across countries and over time: The standardized world income inequality database. Social Science Quarterly 101(3): 1183-1199.

Spilker, Gabriele. 2012. Helpful organizations: Membership in inter-governmental organizations and environmental quality in developing countries. British Journal of Political Science 42(2): 345-370.

Spilker, Gabriele. 2013. Globalization, political institutions, and the environment in developing countries. London: Routledge.

Stadelmann-Steffen, Isabelle, 2011. Citizens as veto players: Climate change policy and the constraints of direct democracy. Environmental Politics 20(4): 485-507.

Steinberg, Paul. 2015. Who rules the Earth? How social rules shape our planet and our lives. Oxford: Oxford University Press.

Swainson, Luke, and Sango Mahanty. 2018. Green economy meets political economy: Lessons from the "Aceh Green” initiative, Indonesia. Global Environmental Change 53: 286-295. 
Torras, Mariano, and James K. Boyce. 1998. Income, inequality, and pollution: a reassessment of the environmental Kuznets curve. Ecological Economics 25(2) 147-160.

Treisman, Daniel. 2020. Economic development and democracy: Predispositions and triggers. Annual Review of Political Science 23(1): 241-257.

Veblen, Thorstein. 2005. The theory of the leisure class: An economic study of institutions. New Delhi: Aakar Books.

Ward, Hugh. 2006. International linkages and environmental sustainability: The effectiveness of the regime network. Journal of Peace Research 43( 2): 149-166.

Ward, Hugh. 2008. Liberal democracy and sustainability. Environmental Politics 17(3): 386409.

Ward, Hugh, Xun Cao, and Bumba Mukherjee. 2014. State capacity and the environmental investment gap in authoritarian states. Comparative Political Studies 47(3): 309-343.

Winters, Jeffrey A., and Benjamin I. Page. 2009. Oligarchy in the United States? Perspectives on Politics 7(4): 731-751.

World Economic and Social Survey. 2016. Climate change resilience: An opportunity for reducing inequalities. New York: United Nations. 


\section{Online Appendix}

A.1. We examine autocorrelation and present a model with a lagged dependent variable and a Prais-Winsten regression with panel-corrected standard errors.

A.2. We estimate a model with the level of $\mathbf{C O}_{2}$ emissions as an alternative outcome variable.

A.3. We use a generalized method of moments (GMM) dynamic panel estimator for the two different dependent variables.

A.4. In light of the results in the main text, we explore the possibility of a curvilinear effect of population.

A.5. To address concerns about measurement error, we employ a dichotomous specification of Democracy and we consider alternative regime type data.

A.6. As another alternative to the Polity V variable, we use data from the V-Dem Project and also control for the influence of civil society.

A.7. We explore the main effect in the pre- and post-1992 periods, and we plot the interaction coefficients for 20-year rolling intervals.

A.8. We control for state capacity.

A.9. We replaced the year fixed effects by region-year fixed effects.

A.10. An analysis of the moderating influence of economic development.

A.11. We examine the effect of democracy for sub-samples of inequality.

A.12. An alternative measure for globalization that focuses more strongly on economic activity.

A.13. We use multiple imputation.

A.14. We explore a three-way interaction of democracy, inequality, and fossil-fuel rents.

A.15 Analyzing the relationship between income and support for environmental policies at the individual level.

A.15. An overview of the sample of countries in our analyses and a correlation matrix. 
TABLE A1

LAGGED DEPENDENT VARIABLE AND PRAIS-WINSTEN REGRESSION

\begin{tabular}{lcc}
\hline & Model A1 & Model A2 \\
\hline Lagged Dependent Variable & 0.027 & \\
& $(0.028)$ & \\
Carbon Emission Level & -0.481 & -2.354 \\
& $(0.202)^{*}$ & $(0.475)^{*}$ \\
Inequality & -6.409 & -27.028 \\
& $(4.771)$ & $(10.340)^{*}$ \\
Democracy & 0.151 & 0.605 \\
& $(0.079)$ & $(0.149)^{*}$ \\
Inequality * Democracy & -0.376 & -1.330 \\
& $(0.188)^{*}$ & $(0.361)^{*}$ \\
Population (ln) & 2.719 & 1.720 \\
& $(1.320)^{*}$ & $(2.772)$ \\
GDP per capita & 0.035 & 0.043 \\
& $(0.028)$ & $(0.059)$ \\
Globalization & 0.050 & 0.009 \\
& $(0.031)$ & $(0.031)$ \\
\hline Observations & 4,225 & 4,343 \\
Country Fixed Effects & Yes & Yes \\
Year Fixed Effects & Yes & Yes \\
Prob $>$ F & 0.000 & 0.000 \\
Prob $>\chi^{2}$ & & \\
\hline
\end{tabular}

Notes. Table entries are coefficients; standard errors clustered on country in parentheses in Model A1; panel-corrected standard errors in parentheses in Model A2; constant as well as year and country fixed effects included in both models, but omitted from presentation.

$* \mathrm{p}<0.05$ (two-tailed). 


\section{Autocorrelation}

A Wooldridge test suggests that there is first-order autocorrelation. We address this issue in two ways. First, Model A1 comprises a lagged dependent variable, which can reduce the occurrence of autocorrelation. However, as we also include fixed effects, the "cure might be worse than the disease:" the lagged dependent variable correlates with the error term, which can give rise to "Nickell bias." We still explore whether the inclusion of the lagged dependent variable affects our results, although Nickell bias can be ignored with large time periods, which should be given in our context. Second, Model A2 is based on Prais-Winsten regression with panel-corrected standard-error models that assumes - and corrects for - a first-order autocorrelation process. Having said that, neither change in the research design affects our main result as Inequality * Democracy remains negatively signed and statistically significant.

\section{Alternative Dependent Variable and GMM Estimation}

We also replaced the dependent variable by per-capita $\mathrm{CO}_{2}$ emissions, which is a variable that is extensively used in the literature as a proxy for environmental quality. $\mathrm{CO}_{2}$ emissions constitute the major contributing factor of climate change and, in the long run, the aim must be to reduce their absolute level. Hence, instead of the progress-based variable in the main text, Model A3 focuses on the absolute level of carbon emissions per capita. The data are available from the World Bank Development Indicators, with carbon dioxide emissions defined as those stemming from the burning of fossil fuels and the manufacture of cement, including emissions produced 
during the consumption of solid, liquid, and gas fuels and gas flaring. The final outcome variable captures the logged emissions in metric tons per capita.

\section{TABLE A2}

\section{LEVEL OF CARBON EMISSIONS AND GMM ESTIMATION}

\begin{tabular}{|c|c|c|c|}
\hline & Model A3 & Model A4 & Model A5 \\
\hline Lagged Dependent Variable & & $\begin{array}{c}0.025 \\
(0.027)\end{array}$ & $\begin{array}{c}1.031 \\
(0.014) *\end{array}$ \\
\hline Carbon Emission Level & & $\begin{array}{l}-0.507 \\
(0.201)^{*}\end{array}$ & \\
\hline Inequality & $\begin{array}{c}0.072 \\
(0.907)\end{array}$ & $\begin{array}{l}-6.575 \\
(4.722)\end{array}$ & $\begin{array}{c}0.134 \\
(0.126)\end{array}$ \\
\hline Democracy & $\begin{array}{c}0.076 \\
(0.023) *\end{array}$ & $\begin{array}{c}0.170 \\
(0.083)^{*}\end{array}$ & $\begin{array}{l}-0.009 \\
(0.004)^{*}\end{array}$ \\
\hline Inequality * Democracy & $\begin{array}{l}-0.187 \\
(0.056) *\end{array}$ & $\begin{array}{l}-0.425 \\
(0.200) *\end{array}$ & $\begin{array}{l}0.020 \\
(0.009) *\end{array}$ \\
\hline Population (ln) & $\begin{array}{c}0.360 \\
(0.196)\end{array}$ & $\begin{array}{l}2.703 \\
(1.289)^{*}\end{array}$ & $\begin{array}{l}-0.008 \\
(0.027)\end{array}$ \\
\hline GDP per capita & $\begin{array}{l}-0.007 \\
(0.005)\end{array}$ & $\begin{array}{c}0.033 \\
(0.028)\end{array}$ & $\begin{array}{l}-0.002 \\
(0.001)^{*}\end{array}$ \\
\hline Globalization & $\begin{array}{c}0.026 \\
(0.005) *\end{array}$ & $\begin{array}{c}0.050 \\
(0.034) \\
\end{array}$ & $\begin{array}{c}0.001 \\
(0.001)\end{array}$ \\
\hline Observations & 4,457 & 4,225 & 4,343 \\
\hline Country Fixed Effects & Yes & Yes & Yes \\
\hline Year Fixed Effects & Yes & Yes & Yes \\
\hline Prob $>F$ & 0.000 & & \\
\hline Prob $>\chi^{2}$ & & 0.000 & 0.000 \\
\hline
\end{tabular}

Notes. Table entries are coefficients; standard errors clustered on country in parentheses; constant as well as year and country fixed effects included in all models, but omitted from presentation.

$* \mathrm{p}<0.05$ (two-tailed). 
Second, instead of the Prais-Winsten regression and the introduction of a lagged dependent variable, we also considered a generalized method of moments (GMM) dynamic panel estimator. GMM estimation may produce more robust and efficient results than, e.g., Prais-Winsten regression models, and it can be helpful to address potential problems of endogeneity: reverse causation between our main dependent variable (and the one used in Model A3) and several independent variables, including inequality, could be present. GMM estimation can correct for this and issues like trending and path dependencies in the data. We use the Arellano-Bond estimator, which contains both the levels and the first difference equations.

Model A3 in Table A2 presents the findings based on the alternative dependent variable. In Models A4 and A5, we rely on the GMM dynamic panel estimator. In the former model, the dependent variable is our progress item, while we use the level of per-capita $\mathrm{CO}_{2}$ emissions in Model A5. As before, we would expect a negative and significant sign for the interaction effect: and this is given for all estimations in Table A2, highlighting that our main result is robust to using a different dependent variable capturing environmental quality and the Arellano-Bond estimator.

\section{Curvilinear Effect of Population}

The main text's analysis reveals a positive effect of population on carbon emission progress, which may seem counterintuitive at first sight. We interpret this effect as a larger population demanding better environmental quality more strongly, which is then implemented by the government and induces more progress in fighting carbon emissions. However, we also explored 
a curvilinear effect of population by adding its squared term to the explanatory variables. As Model A6 shows, though, neither is our main result affected by this added variable nor do we obtain evidence for a curvilinear effect.

TABLE A3

CURVILINEAR EFFECT OF POPULATION

\begin{tabular}{ll}
\hline & Model A6 \\
\hline Carbon Emission Level & -0.458 \\
& $(0.198)^{*}$ \\
Inequality & -5.341 \\
& $(4.788)$ \\
Democracy & 0.166 \\
& $(0.080)^{*}$ \\
Inequality * Democracy & -0.410 \\
& $(0.191)^{*}$ \\
Population (ln) & 9.710 \\
& $(6.692)$ \\
Population (ln) & -0.213 \\
& $(0.179)$ \\
GDP per capita & 0.028 \\
& $(0.027)$ \\
Globalization & 0.044 \\
& $(0.032)$ \\
\hline Observations & 4,343 \\
Country Fixed Effects & Yes \\
Year Fixed Effects & Yes \\
Prob > F & 0.000 \\
\hline
\end{tabular}

Notes. Table entries are coefficients; standard errors clustered on country in parentheses; constant as well as year and country fixed effects included in the model, but omitted from presentation.

$* \mathrm{p}<0.05$ (two-tailed). 
TABLE A4

\section{ALTERNATIVE SPECIFICATION FOR DEMOCRACY}

\begin{tabular}{ll}
\hline & Model A7 \\
\hline Carbon Emission Level & -0.475 \\
& $(0.214)^{*}$ \\
Inequality & -2.007 \\
& $(4.809)$ \\
Democracy Dummy & 2.991 \\
& $(1.478)^{*}$ \\
Anocracy Dummy & 2.985 \\
& $(1.269)^{*}$ \\
Inequality * Democracy Dummy & -7.082 \\
& $(3.549)^{*}$ \\
Inequality * Anocracy Dummy & -7.333 \\
& $(3.048)^{*}$ \\
Population (ln) & 2.819 \\
& $(1.343)^{*}$ \\
GDP per capita & 0.037 \\
& $(0.028)$ \\
Globalization & 0.041 \\
& $(0.032)$ \\
\hline Observations & 4,343 \\
Country Fixed Effects & Yes \\
Year Fixed Effects & 0.000 \\
Prob $>$ F & Yes \\
\hline
\end{tabular}

Notes. Table entries are coefficients; standard errors clustered on country in parentheses; constant as well as year and country fixed effects included in the model, but omitted from presentation.

$* \mathrm{p}<0.05$ (two-tailed). 


\section{Alternative Specification and Data for Democracy}

In the main models, the regime-type variable is the polity 2 item from the Polity $\mathrm{V}$ data set, which ranges between -10 and 10 . While higher values of this item stand for more democratic polities, measurement error might affect individual values and, thus, their ranking. To address this issue, we constructed two binary variables, which divide the original polity 2 scale into autocracies, anocracies, and full democracies. That is, the variable Democracy Dummy receives a value of 1 for values of 6 and higher on the polity2 variable; the item Anocracy Dummy only scores 1 for values between -6 and 6 on the original polity 2 scale. Otherwise, the two newly created variables are coded as 0 , which leaves full autocracies (those scoring -6 or lower on the polity 2 variable) as the baseline or reference category. We introduce Democracy Dummy and Anocracy Dummy instead of the regime-type variable used in the main text and interact either variable with Inequality. Table A4 summarizes the results. On one hand, Inequality * Democracy Dummy is negatively signed and significant at conventional levels. This suggests that our results are robust. On the other hand, Model A7 also emphasizes that there are crucial differences between anocracies and full autocracies. Anocracies perform better than full authoritarian countries even in the presence of high inequality. We derive this conclusion from the negative and significant effect of Inequality * Anocracy Dummy.

In a related fashion, we also considered a categorical, dichotomous democracy indicator, but from a data source different from Polity V. While the Polity V data provide a democracy index for a broad range of countries and years, the indicator may not be suitable under all circumstances. For example, Vreeland (2008) argues that the Polity data are not suitable for the 
study of civil war onset, as these data do comprise information about political violence to begin with. And Gleditsch and Ward (1997) discuss how a given Polity score can occur due to multiple and partly very different combinations of the index's underlying components (for a more general overview of these discussions, see, e.g., Coppedge et al. 2011; Boix et al. 2013). Against this background, we draw upon the binary variable from Boix et al. (2013: 1523), which defines a country "as democratic if it satisfies conditions for both contestation and participation. Specifically, democracies feature political leaders chosen through free and fair elections and satisfy a threshold value of suffrage." When using the dummy item by Boix et al. (2013), the interaction effect is estimated at -6.949 and is statistically significant at the 8 percent level. As in the main text, we simulate the coefficient of the interaction term 1,000 times using the method in King et al. (2000). Figure A1 presents the results: the simulated effect has an average effect of about -7.010 with only 3.3 percent of the simulated parameters being equal to or greater than 0 . As a result, we conclude that our main finding is robust when using the Boix et al. (2013) data.

\section{Variables from the V-DEM Data Set}

Using the V-DEM data set, ${ }^{12}$ we looked at another alternative for our regime-type variable and an indicator for the strength of civil society. First, for replacing the Polity V variable, one out of the five high-level democracy indicators in V-DEM seems most appropriate for our purposes. The codebook refers to the deliberative principle of democracy, which "focuses on the process by which decisions are reached in a polity. A deliberative process is one in which public

\footnotetext{
${ }^{12}$ Available online at: https://www.v-dem.net/en/.
} 
reasoning focused on the common good motivates political decisions - as contrasted with emotional appeals, solidary attachments, parochial interests, or coercion. According to this principle, democracy requires more than an aggregation of existing preferences. There should also be respectful dialogue at all levels - from preference formation to final decision - among informed and competent participants who are open to persuasion. To make it a measure of not only the deliberative principle but also of democracy, the index also takes the level of electoral democracy into account." We run a separate model for this indicator (with higher values standing for more democratic systems) and, as in the other models, interact it with Inequality. Model A8 presents the results.

Moreover, we consider the strength of civil society. Previous research shows that nongovernmental groups can influence environmental politics at both the output and outcome levels. We capture civil-society strength via another variable from V-DEM: "the participatory principle of democracy emphasizes active participation by citizens in all political processes, electoral and non-electoral. It is motivated by uneasiness about a bedrock practice of electoral democracy: delegating authority to representatives. Thus, direct rule by citizens is preferred, wherever practicable. This model of democracy thus takes suffrage for granted, emphasizing engagement in civil society organizations, direct democracy, and subnational elected bodies." Higher values of this variable stand for more possibilities of civil-society influence. We introduce this variable to our main model (hence, with the Polity V variable for regime type) and Model A9 summarizes the corresponding results. In Model A10, we interact the interact the strength of civil society with Inequality, thus omitting the Polity variable. 


\section{FIGURE A1}

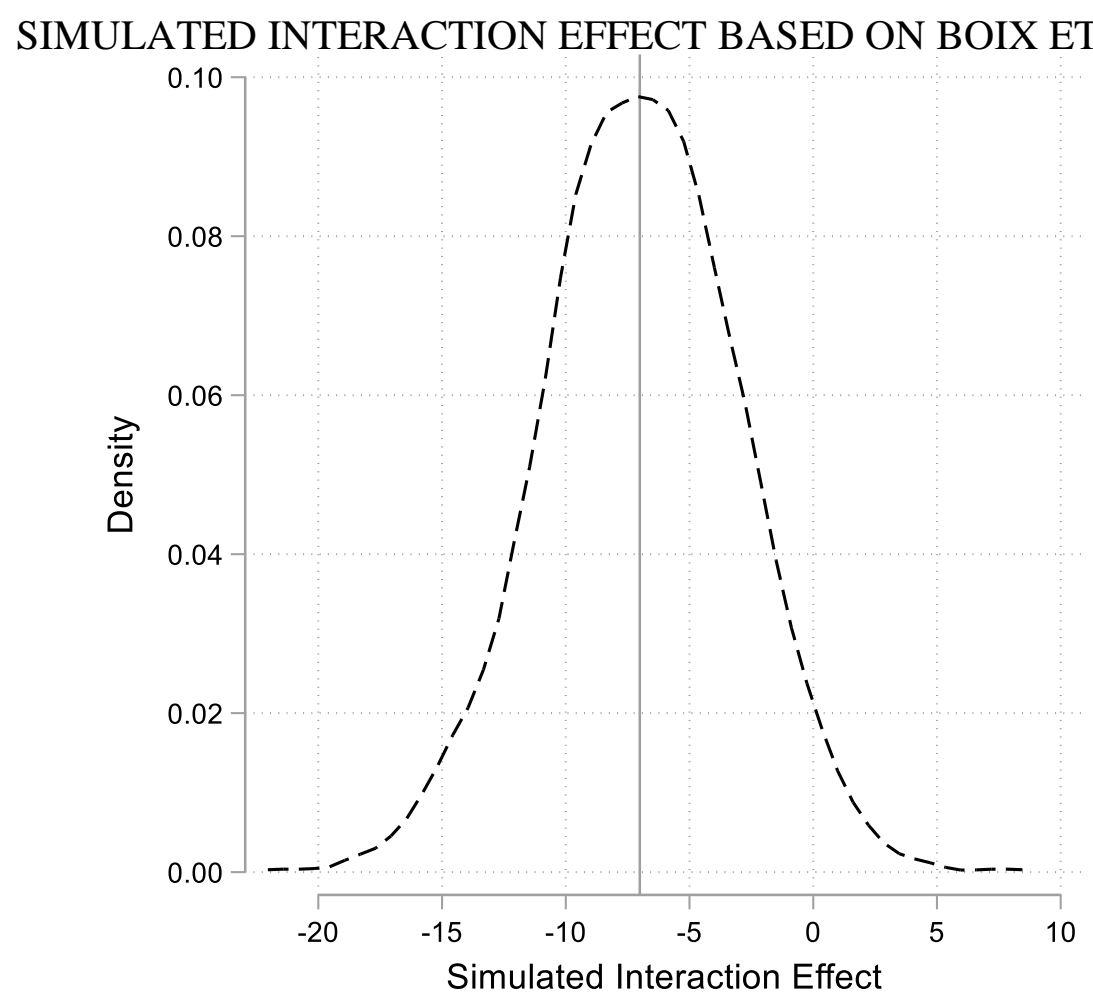

Notes. Graph displays distribution of simulated interaction effect ( $\mathrm{N}=1,000$ simulations); solid line stands for estimated mean value of simulated coefficient (-7.010).

When focusing on Model A8, the interaction term is again negative and significant. However, the overall effect size seems to be more strongly pronounced than in the case of the Polity V variable. The variable on civil society in Model A9 is statistically insignificant and, hence at least in our setup, unlikely to be of crucial importance. The same conclusion applies to the multiplicative specification in Model A10. As a result, also with a view toward unpacking causal mechanisms in more detail, there seems to be an important difference between the effects of deliberation and civil society: the former matters for the relationship between inequality and democracy particularly. 


\section{TABLE A5}

\section{VARIABLES FROM THE V-DEM DATA SET}

\begin{tabular}{|c|c|c|c|}
\hline & Model A8 & Model A9 & Model A10 \\
\hline Carbon Emission Level & $\begin{array}{l}-0.482 \\
(0.217)^{*}\end{array}$ & $\begin{array}{l}-0.485 \\
(0.219)^{*}\end{array}$ & $\begin{array}{l}-0.478 \\
(0.218)^{*}\end{array}$ \\
\hline Inequality & $\begin{array}{l}-3.019 \\
(4.277)\end{array}$ & $\begin{array}{l}-5.630 \\
(4.305)\end{array}$ & $\begin{array}{l}-2.057 \\
(5.439)\end{array}$ \\
\hline Democracy & & $\begin{array}{l}0.156 \\
(0.077)^{*}\end{array}$ & \\
\hline Inequality $*$ Democracy & & $\begin{array}{l}-0.414 \\
(0.195)^{*}\end{array}$ & \\
\hline Deliberative Democracy & $\begin{array}{l}4.694 \\
(2.139)^{*}\end{array}$ & & \\
\hline Inequality $*$ Deliberative Democracy & $\begin{array}{l}-10.040 \\
(4.727)^{*}\end{array}$ & & \\
\hline Civil Society & & $\begin{array}{c}0.931 \\
(0.953)\end{array}$ & $\begin{array}{c}5.157 \\
(3.746)\end{array}$ \\
\hline Inequality $*$ Civil Society & & & $\begin{array}{r}-11.295 \\
(8.117)\end{array}$ \\
\hline Population (ln) & $\begin{array}{l}2.657 \\
(1.263)^{*}\end{array}$ & $\begin{array}{l}2.900 \\
(1.325)^{*}\end{array}$ & $\begin{array}{c}2.612 \\
(1.250)^{*}\end{array}$ \\
\hline GDP per capita & $\begin{array}{c}0.032 \\
(0.026)\end{array}$ & $\begin{array}{c}0.036 \\
(0.028)\end{array}$ & $\begin{array}{c}0.033 \\
(0.027)\end{array}$ \\
\hline Globalization & $\begin{array}{l}0.037 \\
(0.031)\end{array}$ & $\begin{array}{l}0.039 \\
(0.031)\end{array}$ & $\begin{array}{c}0.038 \\
(0.030) \\
\end{array}$ \\
\hline Observations & 4,408 & 4,269 & 4,408 \\
\hline Country Fixed Effects & Yes & Yes & Yes \\
\hline Year Fixed Effects & Yes & Yes & Yes \\
\hline Prob $>\mathrm{F}$ & 0.000 & 0.000 & 0.000 \\
\hline
\end{tabular}

Notes. Table entries are coefficients; standard errors clustered on country in parentheses; constant as well as year and country fixed effects included in all models, but omitted from presentation.

$* \mathrm{p}<0.05$ (two-tailed). 
TABLE A6

PRE- AND POST-1992 PERIOD

\begin{tabular}{lc}
\hline & Model A11 \\
\hline Carbon Emission Level & -0.456 \\
& $(0.210)^{*}$ \\
Inequality & -6.135 \\
& $(5.094)$ \\
Democracy & 0.181 \\
& $(0.091)^{*}$ \\
Inequality * Democracy & -0.451 \\
& $(0.215)^{*}$ \\
Post-1992 & -1.403 \\
& $(1.775)$ \\
Inequality * Post-1992 & 2.976 \\
& $(3.588)$ \\
Democracy * Post-1992 & 0.082 \\
& $(0.136)$ \\
Inequality * Democracy * Post-1992 & -0.170 \\
& $(0.299)$ \\
Population (ln) & 2.970 \\
& $(1.487)^{*}$ \\
GDP per capita & 0.042 \\
& $(0.033)$ \\
Globalization & 0.026 \\
& $(0.031)$ \\
\hline Observations & 4,343 \\
Country Fixed Effects & Yes \\
Year Fixed Effects & Yes \\
Prob $>$ F & 0.000 \\
\hline
\end{tabular}

Notes. Table entries are coefficients; standard errors clustered on country in parentheses; constant, year trend, as well as country fixed effects included in the model, but omitted from presentation.

$* \mathrm{p}<0.05$ (two-tailed). 


\section{FIGURE A2}

\section{MARGINAL EFFECTS}
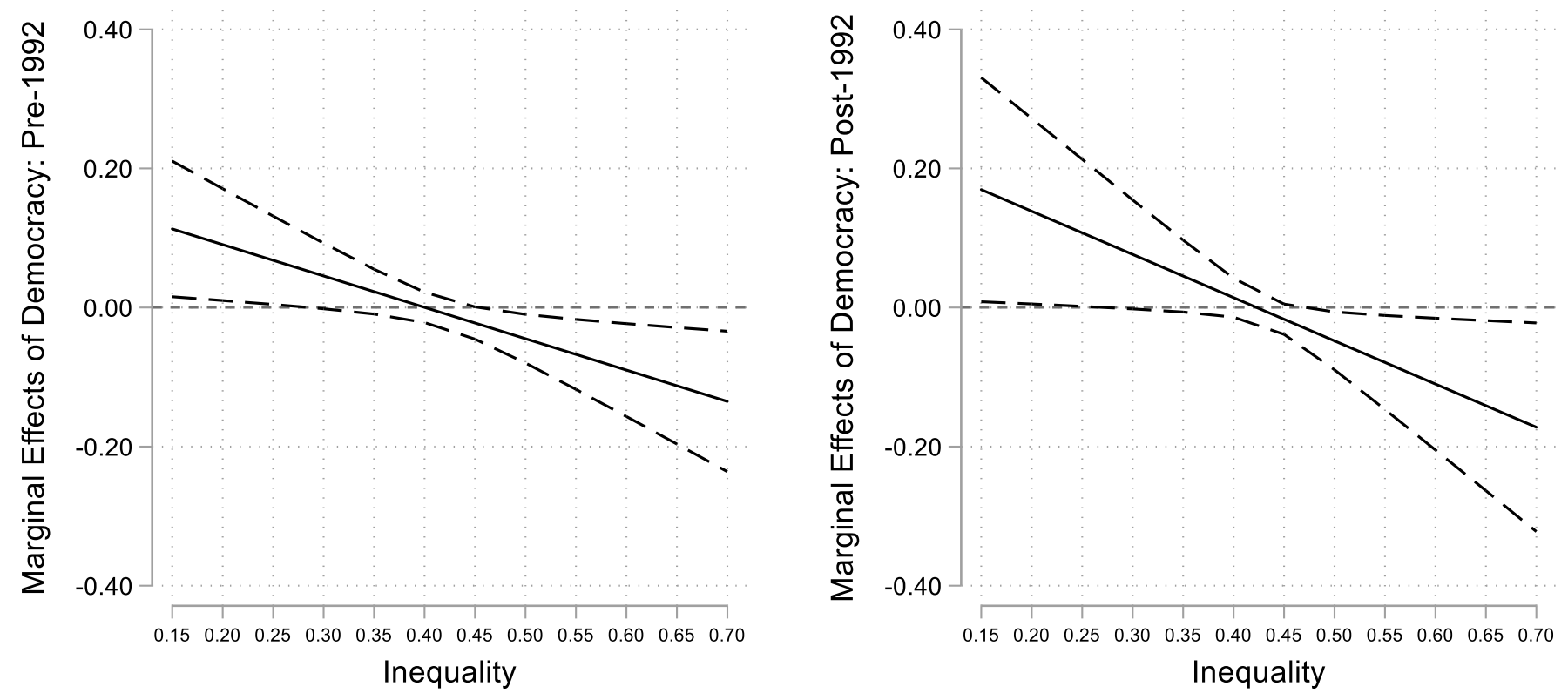

Notes. Graph displays marginal effects of Democracy for given values of Inequality; dashed lines stand for 90 percent confidence interval; horizontal dotted line marks marginal effect of 0 .

\section{Pre- and Post-1992 Period}

Although official concern about climate change can be traced back at least as far as the early 1970s (First Earth Summit, Stockholm) ${ }^{13}$, it may not be reasonable to expect states to introduce policies before the Framework Convention on Climate Change was signed in 1992. As another robustness check, we thus re-run our main model, but now focus on a three-way interaction between regime type, the inequality variable, and a dummy variable distinguishing between the

\footnotetext{
${ }^{13}$ See online at: https://www.un.org/en/chronicle/article/stockholm-kyoto-brief-history-climate-change.
} 
period before and after 1992. The corresponding regression results are summarized in Table A6. Due to the three-way interaction, however, a straightforward interpretation is difficult and, thus, Figure A2 plots the marginal effects of Democracy conditional on Inequality for each time period based on Model A11. Our main finding is robust across the two time periods, though: there is no significant difference between the panels in Figure A2. Indeed the patterns are identical in that democracy first exerts a positive and significant impact on carbon emission progress, i.e., when inequality is low. When increasing inequality in a country, the effect of Democracy becomes negative and statistically significant, however. Also note the effect of Democracy in Table A6: when interacted with the Post-1992 dummy, it is insignificant. The implosion of the Communist regimes in Eastern Europe and the former USSR, which has led to a number of changes in the global level of democracy, could be an issue there.

While we include unit-level fixed effects, it may also be an effort worth making and explore the temporal dimension of our interaction effect in more detail. That is, although the effect is robust across the pre- and post-1992 periods in our data, there may be important yearly changes in the interaction effect between Democracy and Inequality. Following Dorussen and Ward (2010: 38), we evaluate whether Democracy * Inequality has a differing effect over time and, potentially, matter more in more recent years by plotting the interaction coefficients for 20-year rolling intervals: the first estimate is from the regression using data from 1970 until 1990, the second from 1971 until 1991, etc., up to the regression using data between 1996 and 2016. Each interval's starting year is given on the bottom axis. According to Figure A3, the interaction term exerts a negative effect throughout the underlying regressions, but is statistically insignificant at 
the beginning and end of the observation period. Mainly between 1975 (to 1995) and 1993 (to 2013) do we obtain significant estimates.

FIGURE A3

\section{COEFFICIENT ESTIMATES OVER TIME}

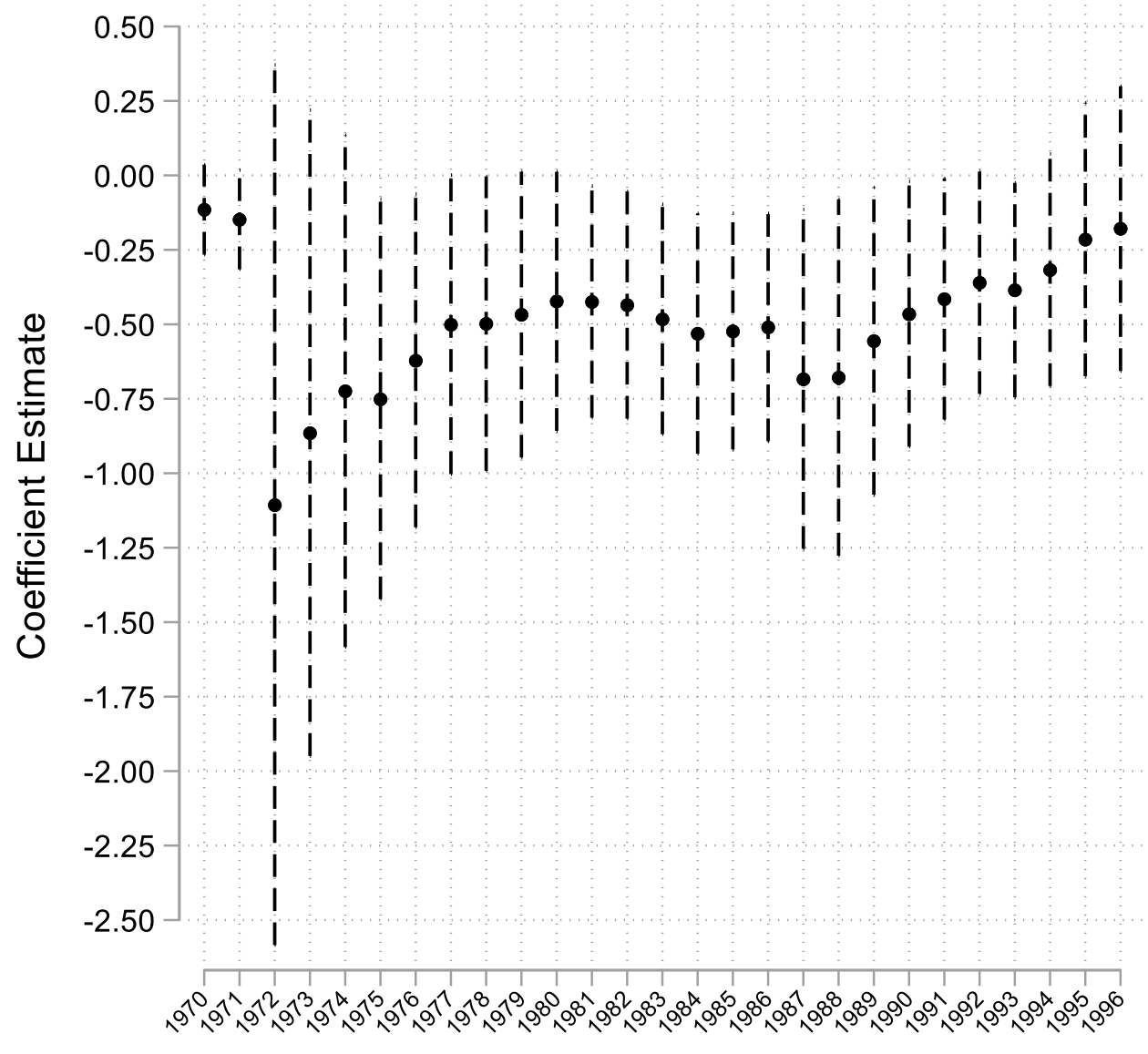

Notes. Graph displays marginal effects of interaction effect over time; dashed lines stand for 90 percent confidence interval. 


\section{Controlling for State Capacity}

State capacity refers to the strength and effectiveness of the state apparatus. The World Bank provides a variable, which (according to their codebook) "combines into a single grouping responses on the quality of public service provision, the quality of the bureaucracy, the competence of civil servants, the independence of the civil service from political pressures, and the credibility of the government's commitment to policies. The main focus of this index is on "inputs" required for the government to be able to produce and implement good policies and deliver public goods." We add this variable to our main model in Table A7, but this does not affect the substance of our main finding.

\section{Region-Year Effects}

The main models comprise fixed effects for countries and years. For Table A8, we have replaced the latter by region-year fixed effects. Countries could influence each other regionally through regional organizations. The EU has done this in the past, and institutions like ASEAN, NAFTA, and the OAS have at least talked about climate change. Region-year fixed effects are a way to control for such influences as we capture any influences that affect all states in a given region simultaneously. We define regions according to the Correlates of War data. Model A13 shows, however, that our core result is unaltered. 
TABLE A7

\section{CONTROLLING FOR STATE CAPACITY}

\begin{tabular}{ll}
\hline & Model A12 \\
\hline Carbon Emission Level & -0.471 \\
& $(0.214)^{*}$ \\
Inequality & -6.259 \\
& $(4.666)$ \\
Democracy & 0.158 \\
& $(0.079)^{*}$ \\
Inequality * Democracy & -0.392 \\
& $(0.191)^{*}$ \\
State Capacity & 0.053 \\
& $(0.100)$ \\
Population (ln) & 2.860 \\
& $(1.358)^{*}$ \\
GDP per capita & 0.035 \\
& $(0.028)$ \\
Globalization & 0.041 \\
& $(0.032)$ \\
\hline Observations & 4,313 \\
Country Fixed Effects & Yes \\
Year Fixed Effects & Yes \\
Prob > F & 0.000 \\
\hline
\end{tabular}

Notes. Table entries are coefficients; standard errors clustered on country in parentheses; constant as well as year and country fixed effects included in the model, but omitted from presentation.

$* \mathrm{p}<0.05$ (two-tailed).

\section{A Moderating Influence of Income?}

As discussed in the main text, democracies vary greatly in their degree of economic inequality and development. Although it might be expected on theoretical grounds that further enfranchisement should lead to greater income equality, democratization may open up market 
opportunities largely benefiting the rich. The literature has not reached a consensus on whether inequality declines with democratization, but we also explore how the degree of economic development moderates a potential relationship between democracy and inequality. To this end, we introduce a three-way interaction between regime type, the inequality variable, and GDP per capita.

TABLE A8

FIXED EFFECTS FOR REGION-YEARS

\begin{tabular}{lc}
\hline & Model A13 \\
\hline Carbon Emission Level & -0.519 \\
& $(0.203)^{*}$ \\
Inequality & -8.407 \\
& $(4.783)$ \\
Democracy & 0.150 \\
& $(0.077)$ \\
Inequality * Democracy & -0.361 \\
& $(0.178)^{*}$ \\
Population (ln) & 1.751 \\
& $(1.260)$ \\
GDP per capita & 0.043 \\
& $(0.033)$ \\
Globalization & 0.032 \\
& $(0.027)$ \\
\hline Observations & 4,343 \\
Country Fixed Effects & Yes \\
Year Fixed Effects & Yes \\
Prob $>$ F & 0.000 \\
\hline
\end{tabular}

Notes. Table entries are coefficients; standard errors clustered on country in parentheses; constant as well as region-year and country fixed effects included in the model, but omitted from presentation.

$* \mathrm{p}<0.05$ (two-tailed). 
Table A9 summarizes the corresponding findings, but a more direct interpretation is given in Figure A4 where we plot the marginal effects of Democracy conditional on Inequality for two scenarios: a low-income country (GDP per capita around 1,000 US Dollars) and a highincome country (GDP per capita around 40,000 US Dollars). When comparing the two panels, it is clear that the effect we theorize largely materializes in low-income countries. In states with more economic development and income, there is little evidence for a negative interaction effect between Democracy and Inequality.

FIGURE A4

\section{MARGINAL EFFECTS}
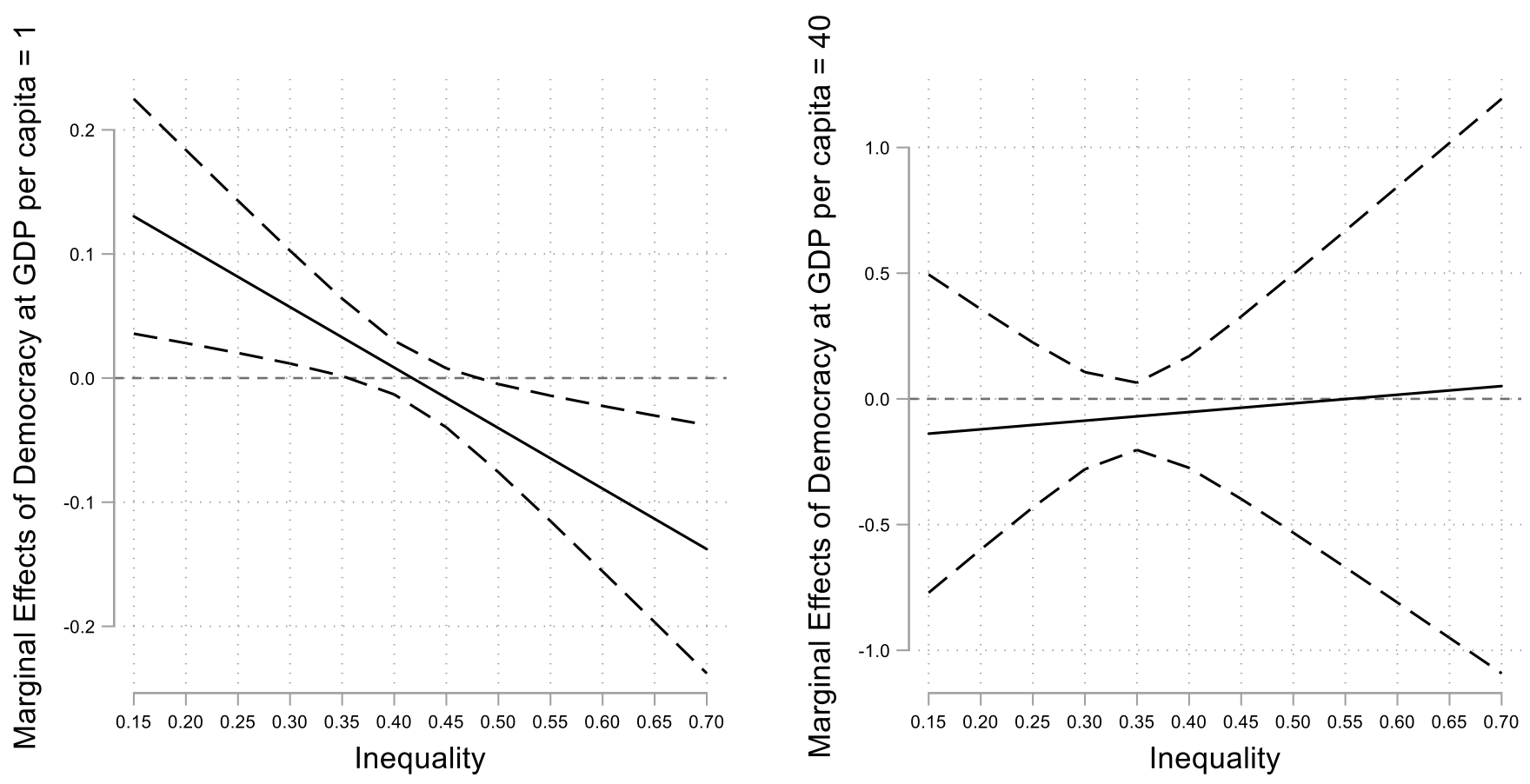

Notes. Graph displays marginal effects of Democracy for given values of Inequality; dashed lines stand for 90 percent confidence interval; horizontal dotted line marks marginal effect of 0 . 
TABLE A9

THREE-WAY INTERACTION WITH INCOME

\begin{tabular}{lc}
\hline & Model A14 \\
\hline Carbon Emission Level & -0.476 \\
& $(0.210)^{*}$ \\
Inequality & -7.090 \\
& $(5.174)$ \\
Democracy & 0.214 \\
& $(0.098)^{*}$ \\
Inequality * Democracy & -0.509 \\
& $(0.239)^{*}$ \\
GDP per capita & 0.081 \\
& $(0.197)$ \\
Inequality * GDP per capita & -0.046 \\
& $(0.574)$ \\
Democracy * GDP per capita & -0.010 \\
& $(0.018)$ \\
Inequality * Democracy * GDP per capita & 0.021 \\
& $(0.052)$ \\
Population (ln) & 2.627 \\
& $(1.339)$ \\
Globalization & 0.039 \\
& $(0.031)$ \\
\hline Observations & 4,343 \\
Country Fixed Effects & Yes \\
Year Fixed Effects & Yes \\
Prob $>$ F & 0.000 \\
\hline
\end{tabular}

Notes. Table entries are coefficients; standard errors clustered on country in parentheses; constant, year trend, as well as country fixed effects included in the model, but omitted from presentation.

$* \mathrm{p}<0.05$ (two-tailed). 
TABLE A10

CONTROLLING FOR ECONOMIC GLOBALIZATION

\begin{tabular}{lc}
\hline & Model A15 \\
\hline Carbon Emission Level & -0.455 \\
& $(0.211)^{*}$ \\
Inequality & -5.193 \\
& $(4.789)$ \\
Democracy & 0.194 \\
& $(0.100)$ \\
Inequality * Democracy & -0.467 \\
& $(0.236)^{*}$ \\
Population (ln) & 2.682 \\
& $(1.356)^{*}$ \\
GDP per capita & 0.027 \\
& $(0.026)$ \\
Economic Globalization & 0.003 \\
& $(0.011)$ \\
\hline Observations & 4,343 \\
Country Fixed Effects & Yes \\
Year Fixed Effects & Yes \\
Prob $>$ F & 0.000 \\
\hline
\end{tabular}

Notes. Table entries are coefficients; standard errors clustered on country in parentheses; constant as well as year and country fixed effects included in the model, but omitted from presentation.

\section{Sub-Samples of Inequality}

Instead of specifying an interaction between Democracy and Inequality, we also looked into partitioning the sample between countries with high inequality and countries of low inequality (see also Bel and Teixidó 2020). As a cut-off point, we focus on the value of 0.35 of the inequality variable, which is just below this item's mean. According to our theoretical argument, 
democracy should be significant for the low-inequality subsample, but should be insignificant for the high-inequality subsample. This approach follows Bel and Teixidó (2020). When doing so, Democracy is indeed positively signed and significant at conventional levels in the former sample's analysis, but negatively signed and insignificant in the latter sample's regression. The corresponding simulated quantities of interest are plotted in Figure A5 (based on King et al. 2000): in the left panel, which is based on the low-inequality sample, only 4.4 percent of the 1,000 simulations produce a negative or zero estimate; in the right panel, however, about 10 percent of the simulations are 0 or positively signed. These results thus mirror the interactive specification we rely on in the main text.

\section{An Alternative Measure for Globalization}

Our globalization measure comprises aspects of political, social, or economic interconnectedness. In a robustness check that is summarized in Table A10, we focus on one of those aspects only, namely economic globalization that is potentially influential for environmental performance. We thus draw on the KOF Globalization data again, but now employ only, which comprises information on trade flows and dependency, foreign direct investment, international debt, trade regulations and taxes, or investment restrictions. ${ }^{14}$ However, our main result is robust and the globalization variable remains statistically insignificant.

14 The full operationalization of the KOF economic globalization item is available here: https://kof.ethz.ch/en/forecasts-and-indicators/indicators/kof-globalisation-index.html. 


\section{FIGURE A5}

\section{SIMULATED DEMOCRACY EFFECTS}
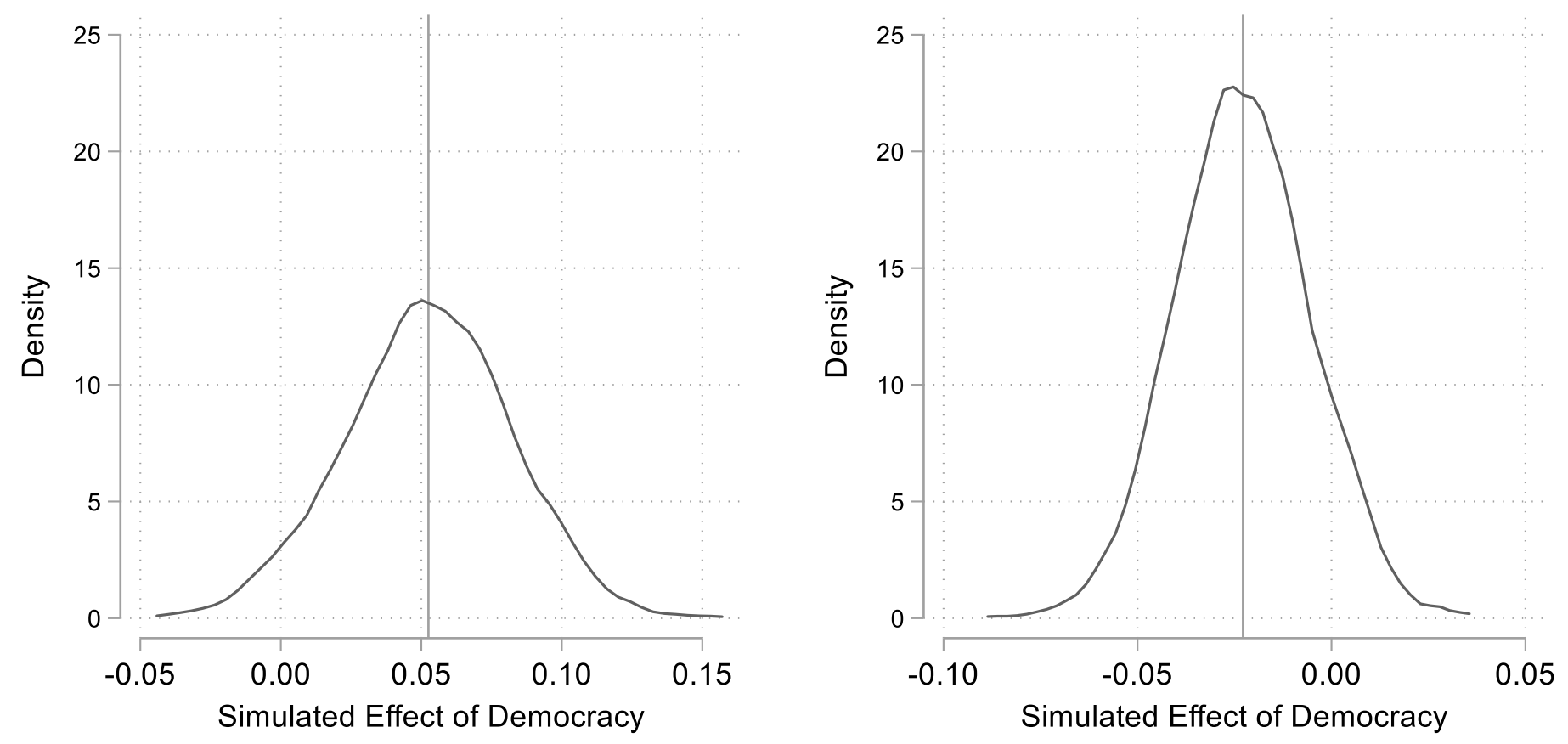

Notes. Graph displays distribution of simulated effects for Democracy ( $\mathrm{N}=1,000$ simulations); solid lines stand for mean value of coefficient (left panel: 0.053; right panel: -0.023).

$* \mathrm{p}<0.05$ (two-tailed).

\section{Multiple Imputation}

Another robustness check makes use of multiple imputation and, thus, acknowledges the persistent uncertainty surrounding our inequality data more than in the other models. For each country-year, the inequality data report 100 values, with the standard deviation increasing as the quality of the data is judged to be lower. Table A11 proceeds in the usual manner, but with multiple imputation by repeatedly drawing samples and pooling the coefficient estimates. Thus, reported standard errors reflect the uncertainties in the data. To achieve convergence in this 
setup, we assume that the disturbance term is first-order autoregressive while including unit-level fixed effects. However, as shown in the Model A16 of this appendix, our main result remains statistically significant at conventional levels.

TABLE A11

MULTIPLE IMPUTATION

\begin{tabular}{lc}
\hline & Model A16 \\
\hline Carbon Emission Level & -0.618 \\
& $(0.043)^{*}$ \\
Inequality & -3.522 \\
& $(3.220)$ \\
Democracy & 0.224 \\
& $(0.095)^{*}$ \\
Inequality * Democracy & -0.523 \\
& $(0.221)^{*}$ \\
Population (ln) & 1.173 \\
& $(0.473)^{*}$ \\
GDP per capita & -0.005 \\
& $(0.013)$ \\
Globalization & 0.004 \\
& $(0.011)$ \\
\hline Observations & 4,188 \\
Imputations & 100 \\
Country Fixed Effects & Yes \\
Year Fixed Effects & Yes \\
Prob $>$ F & 0.000 \\
\hline
\end{tabular}

Notes. Table entries are coefficients; standard errors in parentheses; constant as well as country fixed effects included in the model, but omitted from presentation; disturbance term is first-order autoregressive.

$* \mathrm{p}<0.05$ (two-tailed). 
TABLE A12

THREE-WAY INTERACTION WITH FOSSIL FUEL RENTS

\begin{tabular}{ll}
\hline & Model A17 \\
\hline Carbon Emission Level & -0.515 \\
& $(0.218)^{*}$ \\
Inequality & -7.744 \\
& $(6.035)$ \\
Democracy & 0.232 \\
& $(0.099)^{*}$ \\
Inequality * Democracy & -0.549 \\
& $(0.236)^{*}$ \\
Population (ln) & 5.567 \\
& $(1.996)^{*}$ \\
GDP per capita & 0.103 \\
& $(0.048)^{*}$ \\
Fossil Fuel Production & -0.018 \\
& $(0.204)$ \\
Fossil Fuel Production * Inequality & -0.314 \\
& $(0.548)$ \\
Fossil Fuel Production * Democracy & 0.007 \\
Fossil Fuel Production * Inequality * Democracy & $(0.023)$ \\
& -0.011 \\
Globalization & $(0.057)$ \\
& 0.050 \\
Observations & $(0.034)$ \\
Country Fixed Effects & 2,971 \\
Year Fixed Effects & Yes \\
Prob $>$ F & \multicolumn{1}{c}{ Yes } \\
\hline
\end{tabular}

Notes. Table entries are coefficients; standard errors clustered on country in parentheses; constant as well as year and country fixed effects included in the model, but omitted from presentation.

$* \mathrm{p}<0.05$ (two-tailed). 


\section{Three-Way Interaction with Fossil Fuel Rents}

One criticism of Boyce's (1994) argument about inequality is that the assets of the rich may be lodged in relatively clean industries. This is less likely if the fossil fuel industry is large and profitable. We can control for this with a variable on the sum of oil and coal rents as a percentage of GDP. Oil rents are the difference between the value of crude oil production at world prices and total costs of production. Coal rents are the difference between the value of both hard and soft coal production at world prices and their total costs of production.

We interact this variable (Fossil Fuel Production) with Inequality and Democracy. At any given level of democracy, changing the income distribution could affect the willingness to pay of potential members of a leader's support coalition. How it would do so depends on how potential supporters are located in the income distribution and whether higher income gives rise to a higher or lower willingness to pay. Democratization could also affect the income distribution of potential supporters if it enfranchises lower income groups. Economic inequality giving rise to inequality in power gives the rich leverage, but they will not necessarily have the incentive to use it. Not all environmental public-goods provision necessarily harms their interests. In relation to controlling carbon emissions, the insurance industry and parts of the financial sector concerned with long-run sustainability of returns may well support policies to reduce emissions (Newell and Paterson 2010). On the other hand, if fossil fuel production is important to the economy and gives rise to large rents over and above necessary costs of production and normal profits, it is particularly likely that owners will use any available leverage to rent-seek. The greater the 
degree of inequality the more potential leverage, and the greater the level of fossil fuel rents the greater the incentive.

This could imply that inequality and fossil fuel rents interact to reduce the marginal effect of increasing the level of democracy on progress. We model this with a three-way interaction of Inequality, Democracy, and Fossil Fuel Production (Model A17). However, while the core results are unchanged, the additional interaction terms involving Fossil Fuel Production are all statistically insignificant.

\section{Analysis of Income and Support for Environmental Policies at the Individual Level}

Our argument as well as the empirical interpretation of the results assume that richer people are less likely to support environmental policy due to higher costs. To strengthen our argument, we thus sought to look at individual-level data and test the relationship between income and support for environmental policies. Although we are not aware of individual-level data that cover support for environmental policies and income for a large number of countries, at regular time intervals, for a panel of respondents, we identified the German Longitudinal Election Study (GLES), which asks a panel of respondents about the income and whether they would support climatechange policies even at the expense of economic growth.

Specifically, the GLES ${ }^{15}$ provides longitudinal survey data of several thousand individuals in Germany between 2013 and 2018. That is, the same people are surveyed over 18 waves in this time period, which allows us to track developments over time. The amount of information in this

\footnotetext{
${ }^{15}$ Available online at: https://dbk.gesis.org/dbksearch/SDesc2.asp?DB=D\&no=6827.
} 
data set is higher than in a cross-sectional study, since time-invariant and unobserved individual factors can be controlled for. We also directly observe how a specific phenomenon develops over time and in what order due to the repeated observations of individual responses. The GLES data comprise questions on environmental attitudes and personal income, which - in combination with the longitudinal structure - make them ideal for our purposes. A shortcoming of this analysis is, of course, that we have data for one country only.

When assessing data availability, we could identify several waves $(1-7,10,11,13,16$, and 17) that provide information on the relevant items over the years 2013, 2016, and 2017. Our analysis is based on the same unit of analysis as the GLES, i.e., the individual in each wave: each respondent is paired with each wave in which answers do exist. Due to the scale of our outcome variable (introduced below), we employ OLS regression models with fixed effects for waves and state regions in Germany ("Länder"). The fixed effects control for unobserved heterogeneity and address concerns about the possible non-random selection of states that were surveyed first. We also cluster the standard errors at the individual level and include a temporally lagged dependent variable to capture path dependencies over time.

Our dependent variable is based on the GLES item: "Some people think that fighting climate change should be prioritized even if this lowers economic growth. Others believe that economic growth should be priority, even if this makes it more difficult to fight climate change. What is your opinion on that?" Respondents could assign a value on a scale from 1 to 7 as answers, with 1 standing for "fighting climate change is priority" and 7 signifying "economic growth is priority." We rescaled this variable so that higher values represent a stronger preference for 
fighting climate change (at the expense of economic growth); in turn, lower values capture a stronger preference for economic growth (at the expense of fighting climate change).

TABLE A13

INDIVIDUAL-LEVEL ANALYSIS

\begin{tabular}{lc}
\hline & Model A18 \\
\hline Lagged Dependent Variable & 0.687 \\
Income & $(0.009)^{*}$ \\
& -0.012 \\
Female & $(0.004)^{*}$ \\
& 0.069 \\
Age & $(0.020)^{*}$ \\
& 0.000 \\
Education & $(0.001)$ \\
& 0.047 \\
Religion & $(0.009)^{*}$ \\
& -0.017 \\
Constant & $(0.021)$ \\
& 1.234 \\
Observations & $(0.082)^{*}$ \\
State Fixed Effects & 2,971 \\
Wave Fixed Effects & Yes \\
Prob $>$ F & Yes \\
\hline
\end{tabular}

Notes. Table entries are coefficients; standard errors clustered on individual in parentheses; wave and state fixed effects included in the model, but omitted from presentation.

$* \mathrm{p}<0.05$ (two-tailed). 
Our core explanatory variable, Income, is based on an ordinal scale that ranges between 1 and 13. For that variable, people were asked to provide information on their monthly net household income: 1 stands for below 500 Euros, which is then increased in steps of 250 Euros; as of value 6 (1,500 Euros to 2,000 Euros), the variable is increased in steps of 500 Euros; for higher scores of Income, values are increased in steps of 1,000 or 2,500 Euros. The highest value of that variable, 13, captures household incomes of 10,000 Euros and more. We also control for several socio-demographic variables, which are all taken from the GLES: Female is a binary variable on male (0) and female (1) respondents. Then there is Age, which captures a respondent's age, ranging between 18 and 88 in our sample. Education ranges in [1; 5] and captures the highest educational degree obtained. Finally, Religion is also a dichotomous item that receives a value of 1 if respondents said they see themselves as part of any religion ( 0 otherwise).

Table A13 summarizes the results of the individual-level GLES analysis. In line with our theoretical assumption, Income has a negative effect that is statistically significant. That is, a higher household income is associated with less support to fight climate change at the expense of economic growth. For every unit-increase of Income, environmental support decreases by 0.012 points. We also obtain significant effect estimates for Female and Education, which are in line with what the literature would expect: female respondents and more educated individuals tend to display a stronger support for environmental policies even at the expense of economic growth. 
TABLE A14

SAMPLE COUNTRIES

\begin{tabular}{|c|c|c|}
\hline Afghanistan & Greece & Nigeria \\
\hline Albania & Guatemala & Norway \\
\hline Algeria & Guinea & Oman \\
\hline Angola & Guinea-Bissau & Pakistan \\
\hline Argentina & Guyana & Panama \\
\hline Armenia & Haiti & Papua New Guinea \\
\hline Australia & Honduras & Paraguay \\
\hline Austria & Hungary & Peru \\
\hline Azerbaijan & Iceland & Philippines \\
\hline Bangladesh & India & Poland \\
\hline Belarus & Indonesia & Portugal \\
\hline Belgium & Iran & Qatar \\
\hline Benin & Iraq & Romania \\
\hline Bhutan & Ireland & Russia \\
\hline Bolivia & Israel & Rwanda \\
\hline Botswana & Italy & Saudi Arabia \\
\hline Brazil & Jamaica & Senegal \\
\hline Bulgaria & Japan & Serbia \\
\hline Burkina Faso & Jordan & Sierra Leone \\
\hline Burundi & Kazakhstan & Singapore \\
\hline Cambodia & Kenya & Slovakia \\
\hline Cameroon & Korea & Slovenia \\
\hline Canada & Kuwait & Solomon Islands \\
\hline Cape Verde & Kyrgyzstan & South Africa \\
\hline Central African Republic & Laos & Spain \\
\hline Chad & Latvia & Sri Lanka \\
\hline Chile & Lebanon & Sudan \\
\hline China & Lesotho & Suriname \\
\hline Colombia & Liberia & Swaziland \\
\hline Comoros & Libya & Sweden \\
\hline Congo-Brazzaville & Lithuania & Switzerland \\
\hline Costa Rica & Luxembourg & Taiikistan \\
\hline Croatia & Macedonia & Tanzania \\
\hline Cyprus & Madagascar & Thailand \\
\hline Czech Republic & Malawi & Timor-Leste \\
\hline Côte d'Ivoire & Malaysia & Togo \\
\hline Denmark & Mali & Trinidad and Tobago \\
\hline Diibouti & Mauritania & Tunisia \\
\hline Dominican Republic & Mauritius & Turkey \\
\hline Ecuador & Mexico & Turkmenistan \\
\hline Egypt & Moldova & Uganda \\
\hline El Salvador & Mongolia & Ukraine \\
\hline Estonia & Montenegro & United Kingdom \\
\hline Ethiopia & Morocco & United States \\
\hline Fiii & Mozambique & Uruguay \\
\hline Finland & Myanmar & Uzbekistan \\
\hline France & Namibia & Venezuela \\
\hline Gabon & Nepal & Vietnam \\
\hline Gambia & Netherlands & Yemen \\
\hline Georgia & New Zealand & Zambia \\
\hline Germany & Nicaragua & Zimbabwe \\
\hline Ghana & Niger & \\
\hline
\end{tabular}




\section{Sample of Countries and Correlation Matrix}

Table A14 presents the sample of countries in our data. These countries are then included in most estimations, but there are varying degrees of temporal coverage per state. In Table A15, we show a correlation matrix of the main analyses' variables.

TABLE A15

CORRELATION MATRIX

\begin{tabular}{|c|c|c|c|c|c|c|c|}
\hline & $\begin{array}{c}\text { Carbon Emission } \\
\text { Progress } \\
\end{array}$ & $\begin{array}{c}\text { Carbon } \\
\text { Emission Level } \\
\end{array}$ & Inequality & Democracy & $\begin{array}{c}\text { Population } \\
(\ln )\end{array}$ & $\begin{array}{c}\text { GDP per } \\
\text { capita }\end{array}$ & Globalization \\
\hline Carbon Emission Progress & 1.000 & & & & & & \\
\hline Carbon Emission Level & 0.067 & 1.000 & & & & & \\
\hline Inequality & -0.020 & -0.467 & 1.000 & & & & \\
\hline Democracy & -0.024 & 0.253 & -0.285 & 1.000 & & & \\
\hline Population (ln) & 0.001 & -0.047 & -0.016 & -0.094 & 1.000 & & \\
\hline GDP per capita & 0.054 & 0.685 & -0.563 & 0.427 & -0.096 & 1.000 & \\
\hline Globalization & 0.019 & 0.552 & -0.518 & 0.587 & -0.037 & 0.724 & 1.000 \\
\hline
\end{tabular}

\section{References for the Appendix}

Bel, Germà, and Jordi J. Teixidó. 2020. The political economy of the Paris Agreement: Income inequality and climate policy. Journal of Cleaner Production 258(1): 121002.

Boix, Carles, Michael Miller, and Sebastian Rosato. 2013. A complete data set of political regimes, 1800-2007. Comparative Political Studies 46(12): 1523-1554.

Boyce, James K. 1994. Inequality as a cause of environmental degradation. Ecological Economics 11(3): 169-178.

Coppedge, Michael, John Gerring with David Altman, Michael Bernhard, Steven Fish, Allen Hicken, Matthew Kroenig, Staffan I. Lindberg, Kelly McMann, Pamela Paxton, Holli A. Semetko, Svend-Erik Skaaning, Jeffrey Staton, and Jan Teorell. 2011. Conceptualizing and Measuring Democracy: A New Approach. Perspectives on Politics 9(1): 247-267. 
Dorussen, Han, and Hugh Ward. 2010. Trade networks and the Kantian peace. Journal of Peace Research 47(1): 29-42.

Gleditsch, Kristian S., and Michael D. Ward. 1997. Double take: A reexamination of democracy and autocracy in modern polities. Journal of Conflict Resolution 41(3): 361-383.

King, Gary, Michael Tomz, and Jason Wittenberg. 2000. Making the most of statistical analyses: Improving interpretation and presentation. American Journal of Political Science 44(2): 347361.

Newell, Peter, and Matthew Paterson. 2010. Climate capitalism: global warming and the transformation of the global economy. Cambridge: Cambridge University Press.

Vreeland, James Raymond. 2008. The effect of political regime on civil war: Unpacking anocracy. Journal of Conflict Resolution 52(3): 401-425. 